

\title{
Experimental Investigation on the Shear Crack Development of Shear-Critical High-Strength Reinforced Concrete Beams
}

\author{
Chien-Kuo Chiu ${ }^{1}$, Kai-Ning $\mathrm{Chi}^{2}$ and Fang-Ching Lin $^{3}$
}

\begin{abstract}
The main propose of this work is to investigate the shear crack development and suggest the design formulas that can ensure serviceability and reparability for shear-critical high-strength reinforced concrete (HSRC) beam members based on the experimental data of ten full-size simple-supported beam specimens. According to the experimental results, the design formulas that can ensure the serviceability and reparability are recommended for shear-critical HSRC beam members. Additionally, relationship between shear stresses of member and widths of shear cracks are also built for the quantitative analysis of shear crack development. Based on the crack development of each specimen, the average ratio of the residual total shear crack widths to the residual maximum shear crack width for the HSRC beam specimens is approximately 4.5; then, in the crack-based assessment, this work recommends setting the ratio as 4.0 to estimate residual maximum shear cracking. Additionally, the ratio of maximum peak shear crack width to residual maximum crack width, it can be increased by shortening stirrup spacing and increasing stirrup strength, and its overall average value is 2.44 . This work suggests the applicable value of a HSRC shear-critical beam to be 2.5. Besides of the post-earthquake damage assessment, these results can also be used to build the performance-based design for HSRC structures.
\end{abstract}

\section{Introduction}

Normal-strength Reinforced concrete (RC) is the most widely used construction material owing to its low cost, high durability, ease of maintenance, and usefulness in building unit assembly. However, since its unit weight is high and its strength is lower than that of steel, high-rise buildings above 30 stories are seldom built with normal-strength RC. Additionally, many aging RC structures in Taiwan performed poorly during the $921 \mathrm{Chi}-\mathrm{Chi}$ Earthquake of September 21, 1999, resulting in a significant drop off in the use of this construction material and an increase in the use of steel or steel-reinforced concrete (SRC) as an alternative in high-rise buildings. However, an SRC structure is expensive, and the construction of reinforcing steel bars at SRC beam-column joints is rather complex. For a high-rise building, increasing the strength of $\mathrm{RC}$ can reduce the size of the members or increase the useable interior space to satisfy the same safety requirements. Additionally, precasting an RC structure can shorten the construction period and improve construction quality. A high-strength $\mathrm{RC}$

\footnotetext{
${ }^{1}$ Assoc. Professor, Department of Civil and Construction Engineering, National Taiwan University of Science and Technology, Taipei, Taiwan.

E-mail: ckchiu@mail.ntust.edu.tw

${ }^{2} \mathrm{Ph}$. D. Student, Department of Civil and Construction Engineering, National Taiwan University of Science and Technology, Taipei, Taiwan.

${ }^{3}$ Master Student, Department of Civil and Construction Engineering, National Taiwan University of Science and Technology, Taipei, Taiwan.
}

structure with precast construction can have a long span and be used in office or residential buildings. Therefore, as a promising alternative for buildings, high-strength RC structures with precast construction can compete economically with steel structures.

The definition of high-strength concrete (HSC) has been gradually changed in both use and scope for more than six decades, as mentioned in the document published by the American Concrete Institute (ACI) (ACI 2010). HSC has a continuously expanding range of applications, owing to its highly favorable characteristics such as sufficiently high early age strength, low deflections on account of high modulus elasticity, and high load resistance per unit weight including shear and moment. Therefore, HSC can be used in the construction of skyscrapers and span suspension bridges. HSC is typically defined as concrete whose compressive strength equals or exceeds $60 \mathrm{MPa}$ and less than $130 \mathrm{MPa}$, according to the reference (FIP/CEB 1990). High-strength reinforcement is becoming increasingly common in the construction industry. In Taiwan, high-strength reinforced concrete (HSRC) should include HRC with a specified compressive strength of at least $70 \mathrm{MPa}$ and high-strength reinforcement with a specified yield strength of at least $685 \mathrm{MPa}$. Meanwhile, as the most common specification for concrete engineering design in Taiwan, ACI 318 (2011) sets an upper bound of the yield strength of reinforcing steel bars to $420 \mathrm{MPa}$. Therefore, mechanical models of HSRC members that accurately describe the lateral force-deformation relationship must be developed since the conventional model for normal-strength RC members may not be feasible for evaluating the performance of HSRC members or structures. Owing to their increased strength, the shear 
behavior of HSRC members may differs from that of normal-strength RC members.

According to the design standard published by the Architectural Institute of Japan (AIJ) (AIJ 2010), building performance consists of serviceability, safety and reparability. Restated, in addition to serviceability and safety, reparability should be considered in the performance-based design of buildings.

(a) Serviceability: The scope and level of this property are closely related to times, values, economy, and usage of the building, which can be defined by an owner or user with the appropriate authority and responsibility.

(b) Reparability: After an earthquake, maintenance, including required repair or retrofitting, is performed to ensure the building's serviceability and safety during its service period. The Reparability can be quantified in cost per unit time of the repair or retrofitting.

(c) Safety: Lives must be protected when a building is affected by an external force.

A critical factor in determining the cost of a building over its life cycle, reparability can also be regarded a basic economic performance metric of a building; its importance has become evident in many seismic disaster events, including the Northridge Earthquake (USA, 1994), the Kobe Earthquake (Japan, 1995), and the Chi-Chi Earthquake (Taiwan, 1999). Reparability can ultimately reduce the cost of reconstruction after a seismic disaster. Additionally, a crack-based damage assessment is critical in estimating the cost of repairing a building. Despite the fact that much attention has been paid to crack-based damage assessments of RC members or structures, relevant studies have focused mostly on normal-strength RC and little attention has been paid to HSRC structural members. A crack-based damage assessment can also be performed to estimate post-earthquake residual seismic capacity or to support damage-controlled design (performance-based) for building structure.

Since most studies of HSRC members have focused on their seismic capacity or safety, the main propose of this work is to suggest and investigate design formulas that ensure the serviceability and reparability of HSRC beam members, based on experimental results, the ACI 318 code and the AIJ standard. Additionally, this work focuses on the shear crack development of shear-critical HSRC beam members especially in the relationship between shear stresses and shear crack widths. Ten full-size simple-supported beam specimens (with section dimensions $400 \mathrm{~mm}$ (width) $\times 700 \mathrm{~mm}$ (depth)) with 8 or 12 high-strength reinforcing steel bars of SD685 (685 $\mathrm{MPa}$ of the yield strength) reinforcing steel bars of D25 ( $25 \mathrm{~mm}$ of the diameter) were tested under the four-point loading. The stirrups were SD420 (420 MPa of the yield strength) and SD785 (785 MPa of the yield strength) reinforcing steel bars of D13 (13 $\mathrm{mm}$ of the diameter). The compressive strength of the concrete was measured
Table 1 Definition of damage level of structural members (JBDPA 2001).

\begin{tabular}{|c|l|}
\hline $\begin{array}{c}\text { Damage } \\
\text { Level }\end{array}$ & \multicolumn{1}{c|}{ Description of Damage } \\
\hline I & $\begin{array}{l}\text { Visible narrow cracks on concrete surface. } \\
\text { Crack widths are less than 0.2 mm }\end{array}$ \\
\hline II & $\begin{array}{l}\text { Visible cracks on concrete surfaces. Cracks } \\
\text { widths range from about } 0.2 \text { to 1 mm }\end{array}$ \\
\hline III & $\begin{array}{l}\text { Noticeable wide cracks. Cracks widths range } \\
\text { from about 1 to 2 mm. Localized crushing of } \\
\text { concrete cover }\end{array}$ \\
\hline IV & $\begin{array}{l}\text { Cracks widths are greater than 2 mm. } \\
\text { Crushing of concrete with exposed reinforc- } \\
\text { ing bars. Spalling of cover concrete }\end{array}$ \\
\hline V & $\begin{array}{l}\text { Buckling of reinforcing bars. Crushing of } \\
\text { core concrete. Visible vertical deformation in } \\
\text { columns and/or shear walls. Side-sway, sub- } \\
\text { sidence of upper floors, and/or fracture of } \\
\text { reinforcing bars are observes in some cases. }\end{array}$ \\
\hline
\end{tabular}

to be in the range of $80-100 \mathrm{MPa}$. Stirrup strength, spacing, and tensile reinforcement ratio were used as parameters herein to investigate the development of shear cracks in HSRC shear-critical beam specimens. The definitions of damage levels (Table 1) that were suggested by the Japan Building Disaster Prevention Association (JBDPA) (JBDPA 2001) are adopted. A model that can be used to estimate the residual maximum width of a crack in nonlinear dynamic analysis is required since the definition of damage is based on the residual maximum crack width. Therefore, to quantify damage, experimental results in terms of the shear crack are used to determine the relationship between shear crack width and deformation of a member.

\section{Simulation models of shear-critical RC beam and column specimens with the normal strength}

This section introduces several models have been developed to evaluate the performance of shear-critical RC beam and column members with the normal strength under the lateral loading. A crack-based performance design method, including the crack-controlled design formulas and the relationship between the crack widths and deformation, is also described in this section.

\subsection{Mechanical behavior of shear-critical RC beam and column members}

The monotonic force-displacement relationship of a structural member serves as a primary backbone curve to describe its mechanical behavior under seismic loading. A shear-critical member generally fails before the yield of tensile reinforcement. Moreover, after the maximum strength is reached, the strength will decrease rapidly to a certain point defined as the axial failure. Sezen (2002) proposed a piecewise linear model for the load-deformation response with four pairs of points, which are a combined response of flexure, slip and shear 


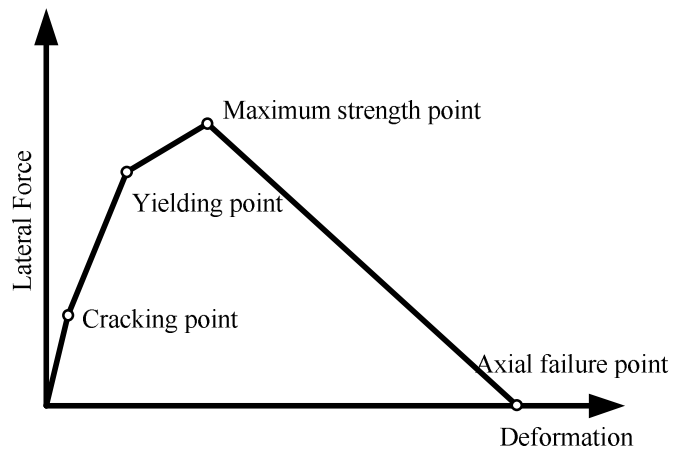

Fig. 1 Lateral force-deformation model for RC shear-critical columns proposed by Sezen (2002).

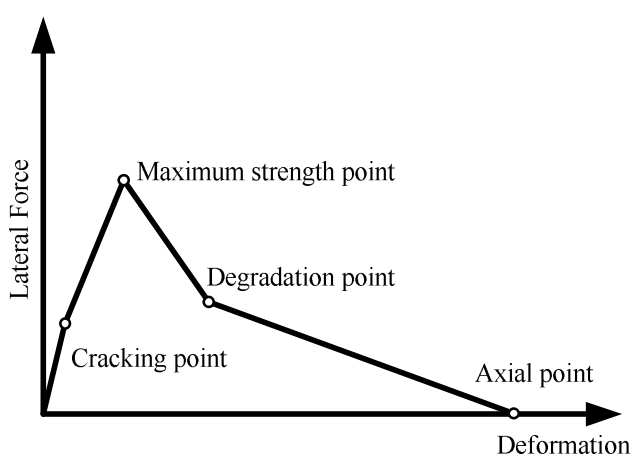

Fig. 2 Monotonic model of the force-deformation relationship for an RC shear-critical member.

deformation (Fig. 1). While using the same piecewise linear model as Sezen (2002), Patwardhan (2005) proposed a different pair of points. By using the modified compression field theory, Setzler (2005) defined the force-deformation relationship up to the maximum strength. In the proposed model, the primary curve can be derived by using Response-2000 software. After the maximum strength point, the model proposed by Patwardhan (2005) is adopted to form the curve of the post-maximum point part. However, owing to the increasing strength, the shear behavior of HSRC structural members differs from that of normal strength RC members. Therefore, a novel monotonic model that describes the force- deformation relationship to elucidate the mechanical behavior of HSRC shear-critical beam and column members is needed for the nonlinear dynamic analysis or seismic damage assessment.

Experimental results indicate that the strength after the maximum point does not decrease linearly to the axial failure (Fig. 2) (Setzler 2005). Additionally, the monotonic shear behavior for an RC member is modeled using one point between the maximum strength point and the axial failure.

This work focuses on the serviceability and reparability of a shear-critical HSRC beam member. Additionally, according to the research (Yoshimura and Takaine 2005), the performance points corresponding to the serviceability and reparability in the member's force-displacement curve are defined within the ultimate strength point. Generally, the cracking point in a force-displacement of a shear-critical $\mathrm{RC}$ member can be estimated as follows:

The cracking point denotes that a member starts to form cracks, either as flexural or shear cracking. The cracking strength at this point represents the minimum of the flexural crack strength, $V_{f c}$, and shear crack strength, $V_{s c}$, as shown in Eq. (1).

$$
\begin{aligned}
& V_{c r}=\min \left(V_{f c}, V_{s c}\right) \\
& V_{f c}=\frac{M_{c r}}{L}=\frac{\frac{f_{r} i_{g}}{0.5 h}+\frac{P h}{6}}{L}=\frac{F_{r} I_{g}}{0.5 L h}+\frac{P h}{6 L} \\
& V s c=\frac{b h}{1.5} \sqrt{f_{t}^{2}+f_{t} \times f_{0}}
\end{aligned}
$$

Where $V_{f c}$ is the flexural cracking strength for a member with the single curvature (if a member with the double curvature, $\left.V_{c r}=M_{c r} / 2 L\right) ; V_{s c}$ is the shear cracking strength; $M_{c r}$ is the flexural cracking moment; $f_{r}$ is the rupture strength of concrete $\left(0.97 \sqrt{f_{c}^{\prime}}\right.$ for the high-strength concrete); $I_{g}$ is the moment inertia of the gross section; $L$ is the span of a member; $h$ is the depth of a member's cross section; $P$ is the axial load; $b$ is the width of a member's cross section; $f_{t}$ is the tensile strength of reinforced concrete $\left(=0.33 \sqrt{f c^{\prime}}\right) ; f_{o}$ is the applied axial stress (AIJ 1999) limits the axial load stress for calculating the flexural cracking strength should not exceed $10 \mathrm{MPa}$ ). Additionally, Equation (3) with a modification coefficient of 0.51 can get relatively conservative results (AIJ 1999).

Deformation of a member at the cracking point can be calculated using Eq. (4). However, the stiffness calculated using Eq. (5) is higher than the stiffness measured from the experiment; generally, Equation (5) needs to be modified as $\varphi_{c r} K$ based on the experiment data $\left(\varphi_{c r}\right.$ is a modificatory factor for the stiffness $K$ ). Additionally, the effect induced by the bond slip on the stiffness is neglected in Eq. (5).

$$
\Delta_{c r}=\frac{V_{c r}}{\varphi_{c r} K}
$$

where $K$ is the stiffness and can be calculated as Eq. (5).

$$
K=\frac{k_{f} \times k_{s}}{k_{f}+k_{s}}
$$

Where $k_{f}$ is the flexural stiffness of a member (for a member with the double curvature, its value is $12 E I_{g} / L^{3}$ ); $k_{s}$ is the shear stiffness (for a member with the double curvature, its value is $G A /(L \kappa)$; $G$ is the shear modulus of concrete; $\kappa$ is the shape factor, can be taken as 1.2).

\subsection{Crack-controlled design formulas for RC beam and column members}

The research (Zakaria et al. 2009) presented an experiment investigation to clarify shear cracking behavior of 
Table 2 Allowable stress of concrete (MPa) (AIJ 2010).

\begin{tabular}{|c|c|c|c|}
\hline \multicolumn{2}{|c|}{ Long-term allowable stress } & \multicolumn{2}{c|}{ Short-term allowable stress } \\
\hline Compression & Shear & Compression & Shear \\
\hline$\frac{1}{3} f_{c}^{\prime}$ & $\min \left\{\frac{1}{30} \mathbf{f}_{\mathbf{c}^{\prime}}^{\prime}\left(0.49+\frac{1}{100} f_{c}^{\prime}\right)\right\}$ & $\begin{array}{c}\text { Long-term allowable } \\
\text { stress } \times 2.0\end{array}$ & $\begin{array}{c}\text { Long-term allowable } \\
\text { stress } \times 1.5\end{array}$ \\
\hline
\end{tabular}

$\mathrm{RC}$ beams. It was found that shear crack width proportionally increases with both the strain of shear reinforcement and with the spacing between shear cracks. The test results also revealed that shear reinforcement characteristics (side concrete cover to stirrup, stirrup spacing and/or stirrup configuration) and longitudinal reinforcement ratio play a critical role in controlling the diagonal crack spacings and openings. Recently, prestressed reinforced concrete (PRC) has been accepted as a reasonable structural member that permits cracking. On the basis of the experiment program including the influence of prestressing force, side concrete cover, stirrup spacing, bond characteristics of stirrup and the amount of longitudinal reinforcement on shear crack width, the research (Silva et al. 2008) revealed that the prestressing force significantly reduced shear crack width in PRC beams as compared to RC beams.

For the shear strength design of an $\mathrm{RC}$ beam or column member, the Japanese design standard (AIJ 2010) considers the long-term and short-term loadings, respectively, to set the design criteria for specified performances, including the serviceability, reparability and safety. For serviceability ensuring, the shear cracking of structural members is not allowed under the long-term loading, including dead and live loadings. For reparability ensuring, the residual maximum shear cracking widths under the short-term loading caused by a medium-magnitude earthquake must be controlled below a specified limit. Furthermore, the assurance of the safety can avoid the shear failure in structural members under the short-term loading caused by a large-magnitude earthquake. According to the Japanese design standard (AIJ 2010), estimating formulas for allowable shear forces corresponding to the assurance of serviceability, reparability and safety are described as follows:

\subsubsection{Allowable shear force corresponding to serviceability ensuring}

In the Japanese design standard (AIJ 2010), for beam and column members, controlling the occurrence of shear cracking under the long-term loading (summation of dead and live loadings) is the basic design concept for serviceability ensuring, as shown in Eq. (6). Furthermore, for a beam member, it can also be designed on the basis of Eq. (7) recommended in the guideline. According the research conducted by Simazaki (2009), if the long-term loading is less than Eq. (7), the maximum shear crack width can be controlled within $0.3 \mathrm{~mm}$.

$$
V_{A L 1}=b j \alpha f_{c s}
$$

Table 3 Allowable stress of reinforcing steel bars (MPa) (AIJ 2010).

\begin{tabular}{|c|c|c|c|c|}
\hline \multirow{2}{*}{ Types } & \multicolumn{2}{|c|}{$\begin{array}{c}\text { Long-term allowable } \\
\text { stress }\end{array}$} & \multicolumn{2}{c|}{$\begin{array}{c}\text { Short-term } \\
\text { allowable stress }\end{array}$} \\
\cline { 2 - 5 } & $\begin{array}{c}\text { Compression } \\
\text { and tension }\end{array}$ & Shear & $\begin{array}{c}\text { Compression } \\
\text { and tension }\end{array}$ & Shear \\
\hline SR & 155 & 155 & 235 & 235 \\
235 & 155 & 195 & 295 & 295 \\
SR & & & & \\
295 & & & & \\
\hline SD & & 195 & 295 & 295 \\
295 & 195 & 195 & 345 & 345 \\
SD & $215(* 195)$ & 390 & 390 \\
345 & $215(* 195)$ & 195 & 490 & 490 \\
SD & $215(* 195)$ & 195 & & \\
390 & & & & 785 \\
SD & & & & \\
490 & 580 & 580 & 785 & \\
\hline SD & & & & \\
785 & & & & \\
\hline
\end{tabular}

( ) for $\geq$ D29

$$
V_{A L 1}=b j\left\{\alpha f_{c s}+0.5 f_{s s}\left(p_{w}-0.002\right)\right\}
$$

where $p_{w}$ is the stirrup ratio $\left(=\frac{a_{w}}{b s} \leq 0.6 \%\right) ; a_{w}$ is the section area of stirrup in the range of stirrup spacing; $s$ is the space of stirrup; $f_{c s}$ is the long-term allowable shear stress of concrete (Table 2); $f_{s s}$ is the long-term allowable tensile stress of stirrup (Table 3); $\alpha$ is the modification factor of the span-depth ratio $\left(=\frac{4}{\frac{M}{V d}+1}(1 \leq \alpha \leq 2) ; M\right.$ is the maximum moment in the long-term loading and $V$ is the maximum shear force in the long-term loading); $b$ is the width of a cross-section;

\subsubsection{Allowable shear force corresponding to reparability ensuring}

In the Japanese design standard (AIJ 2010), for ensuring reparability of beam and column members, Equation (8) can be used to control the damage under the short-term loading of a medium-magnitude earthquake. Additionally, according the research conducted by Simazaki (2009), if the short-term loading of a medium-magnitude is less than Eq. (8), the residual maximum shear crack width can be controlled within $0.3 \mathrm{~mm}$.

$$
V_{S L 1}=b j\left\{\frac{2}{3} \alpha f_{c}+0.5 f_{s}\left(p_{w}-0.002\right)\right\}
$$


where $p_{w}$ is the stirrup ratio $\left(=\frac{a_{w}}{b s} \leq 1.2 \%\right) ; f_{c}$ is the mid-term allowable shear stress (Table 2); $f_{s}$ is the mid-term allowable tensile stress ( $\leq 390 \mathrm{MPa})$ (Table 3).

\subsubsection{Allowable shear force corresponding to safety ensuring}

In the Japanese design guideline (AIJ 2010), for safety ensuring, Equation (9) can be used to design beam and column members under the short-term loading of a large-magnitude earthquake. Additionally, according the research conducted by Simazaki (2009), if the short-term loading induced by a large-magnitude is less than Eq. (9), the maximum shear crack width and residual maximum shear crack width may exceed $1.0 \mathrm{~mm}$ and $0.3 \mathrm{~mm}$, respectively.

$$
V_{S L 2}=b j\left\{\alpha f_{c}+0.5 f_{s}\left(p_{w}-0.002\right)\right\}
$$

\subsection{Shear strength of concrete suggested by ACI 318-11}

In ACI 318 (2011), Equation (10), which is derived on the basis of the diagonal shear crack mechanism, is used to estimate the shear strength of concrete. According to experimental results obtained from a lot of beam specimens without the stirrup, when a beam member has a high tension reinforcement ratio or low span-depth ratio, Equation (10) can give a conservative prediction. Additionally, if the tensile reinforcement ratio is $\leq 0.012$, Equation (10) can be replaced of Eq. (11).

$$
\begin{aligned}
& v_{c}=\left(0.16 \sqrt{f_{c}^{\prime}}+17 \frac{p_{w} V_{u} d}{M_{u}}\right) \leq 0.29 \sqrt{f_{c}^{\prime}} \\
& v_{c}=\left(0.07+8.3 p_{w}\right) \sqrt{f_{c}^{\prime}}
\end{aligned}
$$

where $V_{u}$ is the design shear force of a member and $M_{u}$ is the design moment of a member.

Based on the full-size beam experiment, this work discusses the application of the design formulas on HSRC beam members.

\subsection{Crack-based damage assessment for RC members}

JBDPA (2001) revised guidelines originally developed in 1991 for post-earthquake damage evaluation and retrofitting, based on experiences from disastrous earthquakes such as the 1995 Hyogo-Ken-Nambu (Kobe) Earthquake. The guidelines (JBDPA 2001) categorize damage state for structural members into five levels (Table 1). According to experiences from disastrous earthquakes in Japan, the damage states of vertical members in a building markedly influence the seismic capacity of a building. Therefore, the guidelines identify and classify damage to columns and walls rather than to beams (Maeda and Kang 2009).

Based on the definition of each damage state (Table 1),
Figure 3a shows a ductile member deformed up to its maximum lateral strength after the yielding point of tensile rebars embedded in the member is reached. Obviously, maximum strength implies a relatively small reduction in the strength of a ductile member. Additionally, the damage degree for a brittle member resembles that of a ductile member up to maximum strength (Fig. 3b). However, diagonal or X-shaped cracks may occur in damage levels I, II, and III. After the maximum strength is reached, both lateral and vertical strength may reduce significantly (damage level IV) (Maeda and Kang 2009). Figure 3 illustrates the damaged members for each damage level determined experimentally. The definitions of damage level for the HSRC specimens on beams and columns are based on the definition of damage level of structural members listed in Table 1 (JBDPA 2001). Since the damage level is defined on the basis of the residual crack width, the quantification of the relationship between the residual deformation and residual crack widths is necessary in the performance-based design for HSRC buildings.

Residual deformation of a column and beam member is attributed the residual flexural crack widths, residual shear crack widths, bond slip of main bars and pullout displacement of main bars from the beam-column joint. According to the reference (AIJ 1999), the latter two contributions are negligible and can be disregarded. Therefore, the relationship between the residual deformation and residual crack widths can be simplified as Eq.

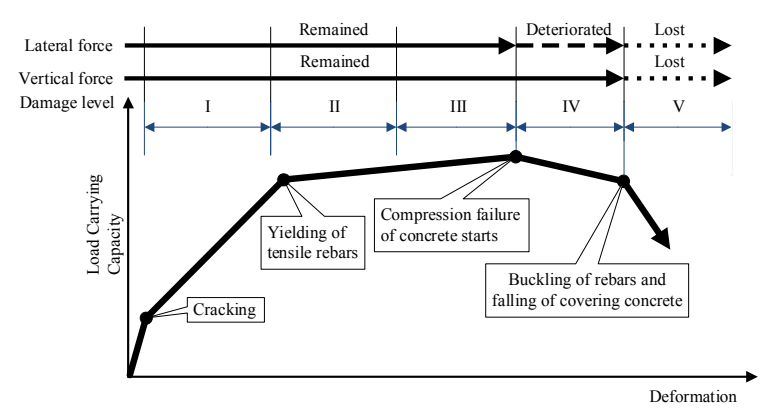

Fig. 3a Approximated lateral force-displacement relationships and damage levels for ductile. members (Maeda and Kang 2009).

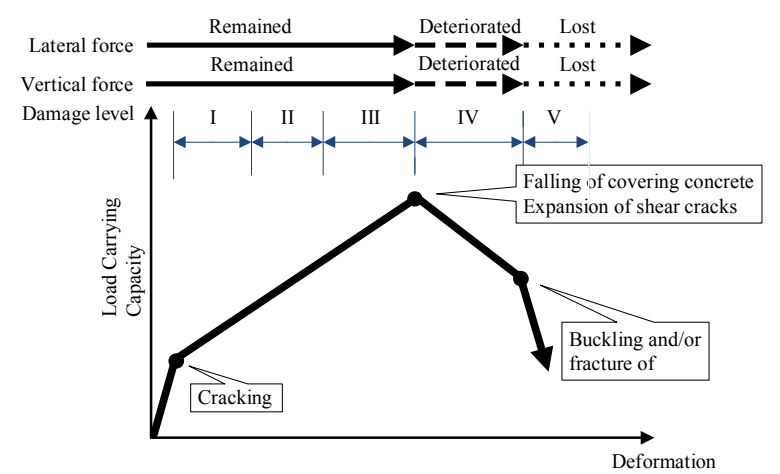

Fig. 3b Approximated lateral force-displacement relationships and damage levels for brittle members (Maeda and Kang 2009). 


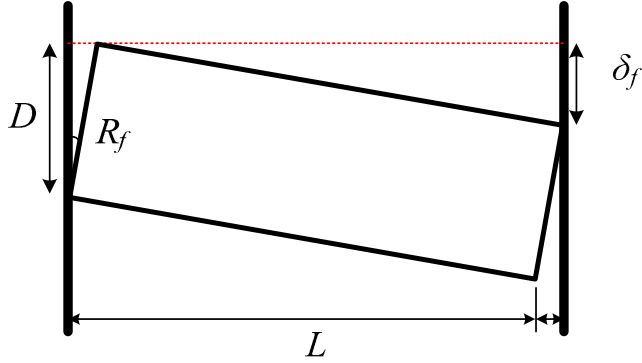

(a) Flexural deformation

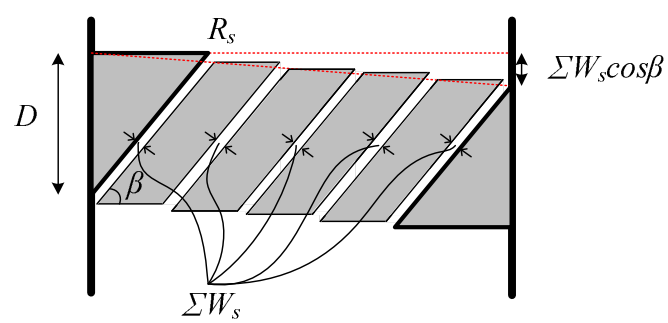

(b) Shear deformation

Fig. 4 Relationship between the residual crack width and residual deformation.

(12). Additionally, this work focuses only on the deformation induced by shear cracking.

$$
R=R_{f}+R_{s}
$$

Figure 4a shows the relationship between the residual flexural crack width and residual deformation. Residual flexural crack widths in the two ends of a member are summed to be $\Sigma W_{f}$; the residual deformation can then be estimated according to the geometric deformation. For convenience, a ratio $n_{f}$ of the residual maximum flexural crack width $W_{f, \max }$ is defined here as the residual total flexural crack widths $\Sigma W_{f}$ to estimate the deformation incurred from the residual flexural crack, as shown in Eq. (13) (AIJ 1999). Experimental results indicate that the ratio $n_{f}$ of a beam member with the normal strength $\mathrm{RC}$ is around 2.0 .

$$
\begin{aligned}
& R_{f}=\frac{\sum w_{f}}{D-x_{n}}=\frac{n_{f} \times W_{f, \text { max }}}{D-x_{n}} \\
& R_{s}=2 \times \frac{\sum W_{s} \times \cos \beta}{L}=2 \times \frac{n_{s} \times W_{s, \text { max }} \times \cos \beta}{L}
\end{aligned}
$$

where $x_{n}$ is the distance between the neutral axis and outermost side of the compressive zone and $\beta$ is the inclined angle of the shear crack (Fig. 4).

The relationship between the residual shear crack widths and residual deformation can be derived using the same concept with the flexural crack (Fig. 4b) (Nakano et al. 2004). In Eq. (14), residual deformation originating from the residual shear crack can be estimated using the ratio $n_{s}$ of the residual maximum shear crack width $W_{s, \max }$ to the residual total shear crack widths $\Sigma W_{s}$ and the residual maximum shear crack width $W_{s, \max }$. Experimental

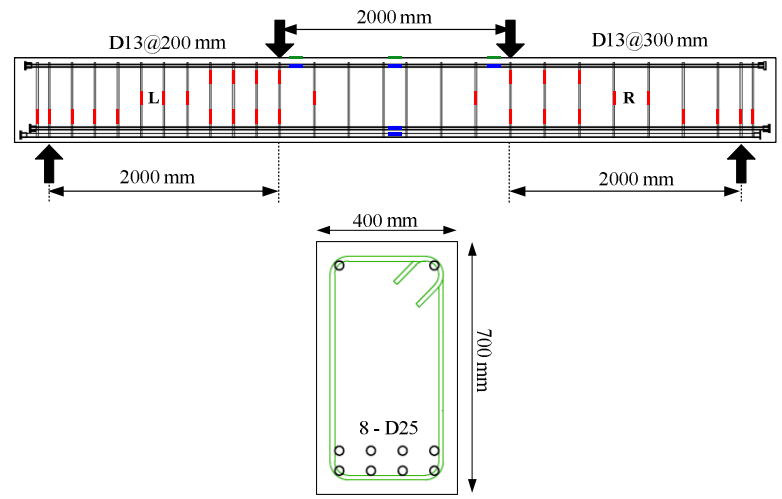

Fig. 5 Typical Design of HSRC beam specimens in the experiment.

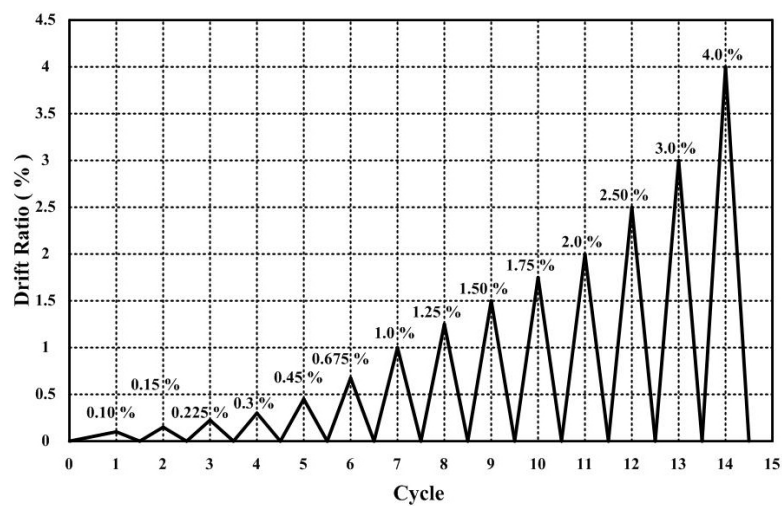

Fig. 6 Loading history for HSRC beam specimens.

results (Nakano et al. 2004) indicate that the ratio $n_{s}$ of beam members with the normal strength $\mathrm{RC}$ is roughly 3 to 4. However, whether it is applicable to the HSRC beam member warrants further study. While focusing only on HSRC shear-critical beam and column members, this work investigates the relationship between the residual deformation and the residual shear crack width by conducting a full-size experiment. Additionally, based on the experimental data, this work also derives a formula to describe the relationship between the residual deformation and residual maximum shear crack.

\section{Experimental setup and results}

This section describes the setup for testing the HSRC beam specimens in this work. Ten full-size beam specimens were designed to investigate the relationship between crack development and damage state. All tests were performed at the National Center for Research on Earthquake Engineering, Taiwan (NCREE).

\subsection{HSRC shear-critical beam specimens}

Ten simple-supported beam specimens were tested using the monotonic four-loading method (Fig. 5). The applied lateral loading was controlled by varying the deformation of the mid-point of each specimen as shown in Fig. 6. The main bars were specified as SD685 of D25, while the stirrups were specified as SD420 and SD785 of D13. The 
equivalent shear regions on the right and left-hand sides of the beam specimens were designed with two stirrup spacings (200 and $300 \mathrm{~mm}$ ). Each specimen was 6600 $\mathrm{mm}$ long. The two equivalent shear regions had a span of $2000 \mathrm{~mm}$, and the equivalent moment region had a span of $2000 \mathrm{~mm}$. The size of the section was $400 \mathrm{~mm}$ (width) $\times 700 \mathrm{~mm}$ (depth); the protective layer was $40 \mathrm{~mm}$ thick, and the measured compressive strength of the concrete was approximately 80-100 MPa. Stirrup strength, spacing, and tension reinforcement ratio are used as parameters, and the above specimen is used to discuss the development of shear cracks in HSRC shear-critical beams. The effect of these parameters on shear crack development is elucidated and the quantitative relationship between the residual crack width and residual deformation is regressed to conduct a damage assessment of HSRC beam members. Additionally, the formulas for estimating shear forces that ensure serviceability and reparability, described in Section 2, are discussed and their application to HSRC beam members is experimentally studied. Tables $\mathbf{4}$ and $\mathbf{5}$ list the required struc- tural properties of the beam specimens for the mechanical analysis and mechanical properties of reinforcing steel bars, respectively.

\subsection{System for measuring deformation and crack widths}

To measure crack development, each specimen was brushed with white cement paint and $100 \times 100 \mathrm{~mm}$ grid lines were drawn on it before testing. The actual stirrup position was marked on each specimen. The crack widths were measured using a microscope with a measurement resolution of $0.01 \mathrm{~mm}$. The maximum crack width at a specified peak deformation and the residual crack width (the applied loading was set back to zero) at each measurement point were recorded in the experiment. The main purpose of eth experiment was to measure shear cracks. The methods for measuring cracks of various types at various positions are described as follows (Fig. 7):

(1) Flexural crack: a crack occurs where the bending moment stress is at its maximum.

Table 4 Properties of HSRC Beam specimens.

\begin{tabular}{|c|c|c|c|c|c|c|c|c|c|c|}
\hline \multirow{2}{*}{ Spec. } & \multirow{2}{*}{ Failure mode } & \multirow{2}{*}{$\mathrm{N}^{*}$} & \multicolumn{2}{|c|}{$\mathrm{s}(\mathrm{cm})$} & \multirow{2}{*}{$\begin{array}{c}f_{\mathrm{y}}^{*} \\
(\mathrm{MPa})\end{array}$} & \multirow{2}{*}{$\begin{array}{c}f_{\mathrm{yt}}^{*} \\
(\mathrm{MPa})\end{array}$} & \multirow{2}{*}{$\begin{array}{c}f_{\mathrm{c}}^{\prime} \\
(\mathrm{MPa})\end{array}$} & \multirow{2}{*}{$\begin{array}{c}\rho_{\mathrm{t}} \\
(\%)\end{array}$} & \multicolumn{2}{|c|}{$\mathrm{p}_{\mathrm{w}}(\%)$} \\
\hline & & & left & right & & & & & left & right \\
\hline $8 \mathrm{H} 70$ & Flexural-shear failure & 8 & 20 & 30 & 685 & 785 & 88.7 & 1.7 & 0.32 & 0.21 \\
\hline $8 \mathrm{H} 100$ & Flexural-shear failure & 8 & 20 & 30 & 685 & 785 & 98.6 & 1.7 & 0.32 & 0.21 \\
\hline $8 \mathrm{~N} 70$ & Shear failure & 8 & 20 & 30 & 685 & 420 & 93.5 & 1.7 & 0.32 & 0.21 \\
\hline $8 \mathrm{~N} 100$ & Shear failure & 8 & 20 & 30 & 685 & 420 & 103.5 & 1.7 & 0.32 & 0.21 \\
\hline $8 \mathrm{NS} 100$ & Shear failure & 8 & - & - & 685 & - & 105.1 & 1.7 & - & - \\
\hline $12 \mathrm{H} 70$ & Shear failure & 12 & 20 & 30 & 685 & 785 & 88.7 & 2.5 & 0.32 & 0.21 \\
\hline $12 \mathrm{H} 100$ & Shear failure & 12 & 20 & 30 & 685 & 785 & 98.6 & 2.5 & 0.32 & 0.21 \\
\hline $12 \mathrm{~N} 70$ & Shear failure & 12 & 20 & 30 & 685 & 420 & 93.5 & 2.5 & 0.32 & 0.21 \\
\hline $12 \mathrm{~N} 100$ & Shear failure & 12 & 20 & 30 & 685 & 420 & 103.5 & 2.5 & 0.32 & 0.21 \\
\hline $12 \mathrm{NS} 100$ & Shear failure & 12 & - & - & 685 & - & 105.1 & 2.5 & - & - \\
\hline
\end{tabular}

*Design value of the yield strength for the reinforcing steel.

Table 5a Properties of reinforcing steel bars used in the $\mathrm{H}$-series of specimens.

\begin{tabular}{|c|c|c|c|c|c|c|}
\hline \multicolumn{2}{|c|}{ Specifications } & Yield strength $(\mathrm{MPa})$ & $\begin{array}{l}\text { Tensile strength } \\
(\mathrm{MPa})\end{array}$ & Elongation ratio (\%) & $\begin{array}{l}\text { Tension-yield } \\
\text { ratio }\end{array}$ & $\begin{array}{c}\text { Upper bound of the } \\
\text { yield strain }\end{array}$ \\
\hline \multirow{2}{*}{ No. } & \multirow{2}{*}{ Types } & Testing value & Testing value & Testing value & Testing value & Testing value \\
\hline & & Specified value & Specified value & Specified value & Specified value & Specified value \\
\hline \multirow{2}{*}{ D13 } & \multirow{2}{*}{ SD785 } & 851 & 1022 & 14 & 1.2 & - \\
\hline & & $\geq 785$ & $\geq 930$ & $\geq 8$ & - & - \\
\hline \multirow{2}{*}{ D25 } & \multirow{2}{*}{ SD685 } & 730 & 952 & 14 & 1.3 & 0.022 \\
\hline & & $685-785$ & $\geq 860$ & $\geq 10$ & $\geq 1.25$ & $\geq 0.014$ \\
\hline
\end{tabular}

${ }^{*}$ Tension-yield ratio $=$ tensile strength $/$ yield strength.

Table 5b Properties of reinforced steel bars used in the N- and NS-series of specimens.

\begin{tabular}{|l|c|c|c|c|c|c|}
\hline \multicolumn{2}{|c|}{ Specifications } & Yield strength (MPa) & $\begin{array}{c}\text { Tensile strength } \\
(\mathrm{MPa})\end{array}$ & Elongation ratio (\%) & $\begin{array}{c}\text { Tension-yield ratio } \\
\text { No. }\end{array}$ & $\begin{array}{c}\text { Upper bound of the } \\
\text { yield strain }\end{array}$ \\
\hline \multirow{2}{*}{ No. } & \multirow{2}{*}{ Types } & Testing value & Testing value & Testing value & Testing value & Testing value \\
\cline { 3 - 6 } D13 & \multirow{2}{*}{ SD420 } & Specified value & Specified value & Specified value & Specified value & Specified value \\
\cline { 3 - 7 } & \multirow{2}{*}{ D25 } & SD685 & $420-540$ & 684 & 19 & 1.41 \\
\cline { 3 - 7 } & & 737 & $\geq 550$ & 10 & - \\
\hline
\end{tabular}

*Tension-yield ratio $=$ tensile strength $/$ yield strength. 


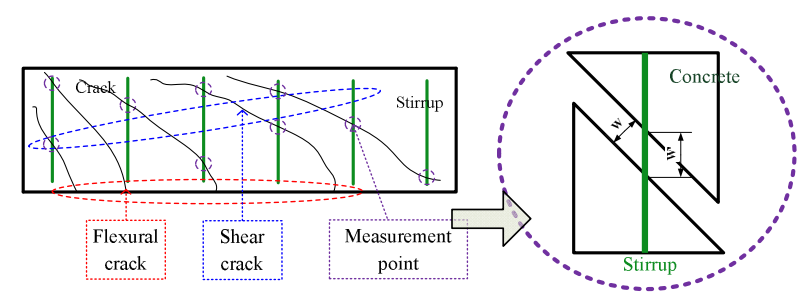

Fig. 7 Measure points for various crack types.

(2) Shear crack: a crack occurs where the shear stress is at its maximum. Additionally, the distance at the intersection between the shear crack and the stirrup, including the shear crack width $W$ and the displacement parallel to the stirrup $W^{\prime}$, is measured.

Since the equivalent shear regions on the right and left-hand sides of the beam specimens were designed with two stirrup spacings, named as L-20 and R-30 regions, the hysteresis loops and envelope lines were drawn for the critical region in one specimen, respectively.

\subsection{Experimental results}

Except specimen $12 \mathrm{H} 100$, whose strength exceeds the capacity of the experimental equipment, the hysteresis loops and envelope lines of each specimen were drawn for the critical region, e.g., R-30 region. Table 6 lists the shear crack strength and maximum shear force for each specimen. On the basis of the failure mode, these specimens can be divided in two groups, as follows:

\section{(1) Shear failure mode}

For specimen of 12NS100 (non-stirrup beam), at the deformation of $0.60 \%$ of the specimen, the primary shear crack, whose width is approximately $1.8 \mathrm{~mm}$, occurred in the L-side region. Additionally, up to the deformation $0.8 \%$, the R-side region also had the primary shear crack; then, the applied loading decreased from $292.0 \mathrm{kN}$ to $236.0 \mathrm{kN}$ suddenly. Since the specimen had no stirrup, at the deformation of $1.00 \%$, the primary shear crack in the R-side of the specimen extended upwards the compression zone of concrete, as shown in Fig. 8. Accordingly, the compression zone of concrete was

Table 6 Shear crack force and maximum shear force for each specimen.

\begin{tabular}{|c|c|c|c|}
\hline \multirow{2}{*}{ Spec. } & \multicolumn{2}{|c|}{ Shear crack force $(\mathrm{kN})$} & \multirow{2}{*}{$\begin{array}{c}\text { Maximum } \\
\text { Shear force } \\
(\mathrm{kN})\end{array}$} \\
\hline & L-side & R-side & \\
\hline $8 \mathrm{H} 70$ & 205.49 & 209.63 & 815.6075 \\
\hline $8 \mathrm{H} 100$ & 195.96 & 198.18 & 879.5499 \\
\hline $8 \mathrm{~N} 70$ & 211.52 & 211.86 & 747.5391 \\
\hline $8 \mathrm{~N} 100$ & 192.78 & 195.63 & 623.4787 \\
\hline $8 \mathrm{NS} 100$ & 198.82 & 196.59 & 248.4361 \\
\hline $12 \mathrm{H} 70$ & 242.64 & 243.35 & 1066.2672 \\
\hline $12 \mathrm{H} 100$ & 245.19 & 175.27 & 1048.4556 \\
\hline $12 \mathrm{~N} 70$ & 250.27 & 244.62 & 853.7816 \\
\hline $12 \mathrm{~N} 100$ & 233.75 & 230.94 & 716.3635 \\
\hline $12 \mathrm{NS} 100$ & 213.43 & 158.41 & 292.0123 \\
\hline
\end{tabular}

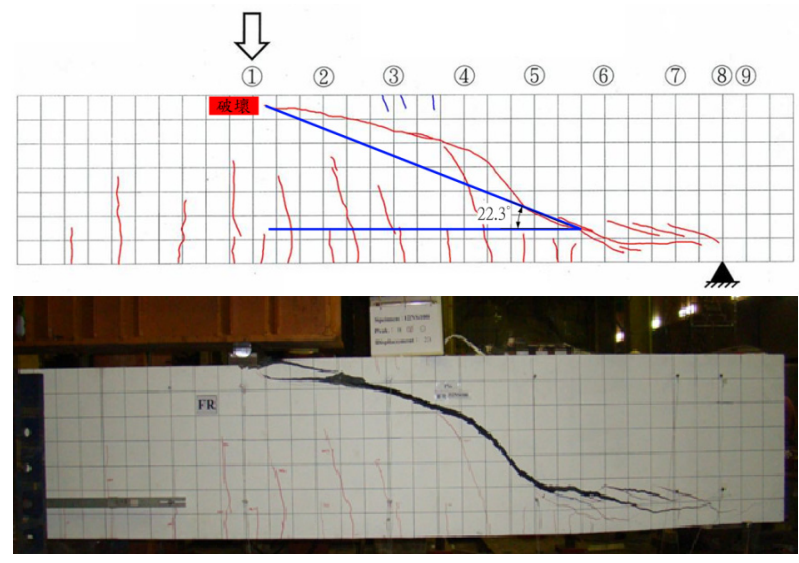

Fig. 8 Shear crack development in the $\mathrm{R}-30$ region of $12 \mathrm{NS} 100$.

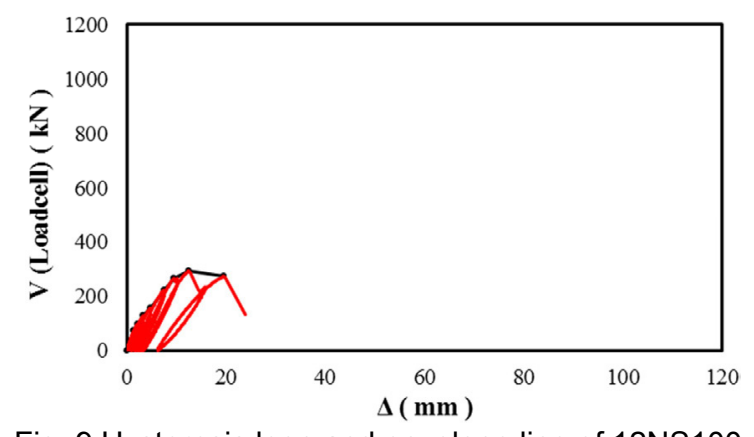

Fig. 9 Hysteresis loop and envelope line of 12NS100.

crashed to cause the specimen's strength lost. The primary shear crack also extended along main bars to the support horizontally. At the last applied displacement, the specimen's strength decreased from $272.9 \mathrm{kN}$ to $134.2 \mathrm{kN}$ and its failure can be concluded to the shear-compression failure. Figure 9 shows the relationship between the strength and deformation of $12 \mathrm{NS} 100$. The crack development of $8 \mathrm{NS} 100$ (non-stirrup beam) is similar to the specimen of $12 \mathrm{NS} 100$. Its failure mode is the shear-compression failure and the specimen's maximum strength is $248.4 \mathrm{kN}$ at the deformation of $0.8 \%$.

The stirrups of the four specimens $12 \mathrm{~N} 70,12 \mathrm{~N} 100$, $8 \mathrm{~N} 70$ and $8 \mathrm{~N} 100$ have normal strength $(420 \mathrm{MPa})$. According to the experimental results, they similarly develop shear cracks. For example, for specimen 12N70 (Fig. 10), a shear crack was observed at a deformation of $0.30 \%$. At a deformation of $1.25 \%$, a primary shear crack with a width of approximately $1.25 \mathrm{~mm}$ formed in the R-side region of the specimen and a primary shear crack with a width of $0.51 \mathrm{~mm}$ formed in the L-side region. When the deformation had reached $2.00 \%$, the primary shear crack in the R-side region of the specimen extended up the compression zone of concrete. Therefore, the compression zone of concrete crashed causing the strength of the specimen to be lost; the applied loading then suddenly fell from the maximum of $853.8 \mathrm{kN}$ to $536.0 \mathrm{kN}(62.8 \%$ of the maximum strength). In the final step, with a deformation of $2.50 \%$, some of the com- 


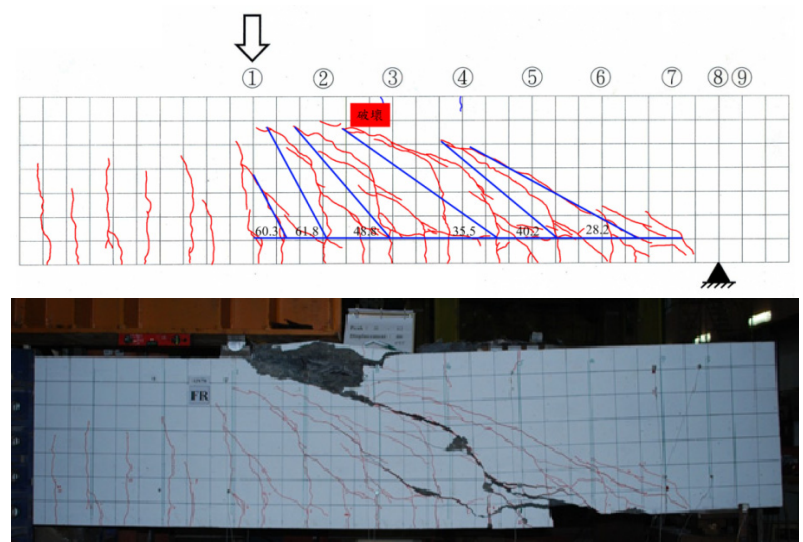

Fig. 10 Shear crack development of the $\mathrm{R}-30$ region of 12 N70.

pressive reinforcement broke and the shear cracks extended horizontally along the main bars to the support. Figure 11 plots the relationships between the strength and deformation of 12N70, 12N100, 8N70 and 8N100.

For the specimen of $12 \mathrm{H} 70$, a shear crack formed at a deformation of $0.30 \%$. The primary shear crack formed in the R-30 region of the specimen at a deformation of $1.25 \%$ and its width had grown to $2.15 \mathrm{~mm}$ at a deformation of $2.00 \%$ and a shear force of $897.4 \mathrm{kN}$. When the deformation reached $2.50 \%$, the primary shear crack in the R-30 region of the specimen extended up the compression zone of concrete and extended horizontally along the main bars to the support. Accordingly, the compression zone of concrete crashed and the compressive reinforcement broke, causing the specimen to lose strength suddenly; then, the applied loading suddenly fell from the maximum strength of $1066.3 \mathrm{kN}$ to $517.9 \mathrm{kN}$ (48.6\% of the maximum strength) (Figs. 12 and 13).

\section{(2) Flexural-shear failure mode}

According to the experimental observations of the specimens of $8 \mathrm{H} 70$ and $8 \mathrm{H} 100$, the mechanical behavior of these two specimens includes flexural-shear failure and cracks in them development similarly. For example, when the applied displacement deforms $8 \mathrm{H} 70$ by $0.30 \%$ (Fig. 14), a shear crack occurred. Up to a deformation of $4.0 \%$, the shear crack with the maximum width of approximately $1.4 \mathrm{~mm}$ formed in the R-side region of the specimen while the maximum width of the flexural cracks in the moment-equivalent region was $2.0 \mathrm{~mm}$. The strength reached the maximum of $815.6 \mathrm{kN}$. At the point of maximum strength, the compression zone of concrete in the moment-equivalent region crushed and the strength fell to $696.3 \mathrm{kN}(85.4 \%$ of the maximum strength). Figure 15 plots the relationship between the strength and the deformation of $8 \mathrm{H} 70$ and $8 \mathrm{H} 100$. For $8 \mathrm{H} 100$, the maximum strength was approximately 879.5 $\mathrm{kN}$ at a deformation of $5.0 \%$. At the maximum strength point, the compression zone of the concrete in the moment-equivalent region crashed and the strength fell to $767.9 \mathrm{kN}$ (87.3\% of the maximum strength).

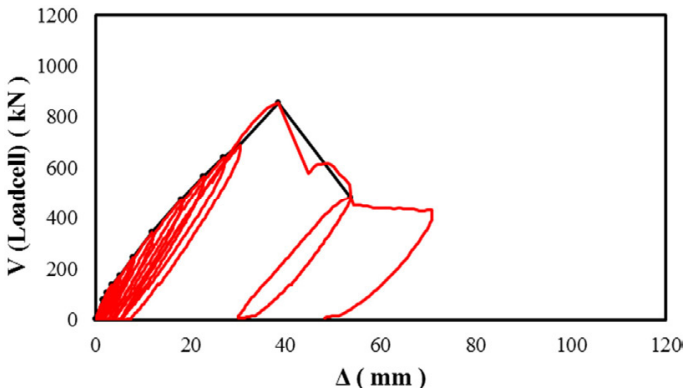

(a) $12 \mathrm{~N} 70-\mathrm{R}(\mathrm{s}=30 \mathrm{~cm})$

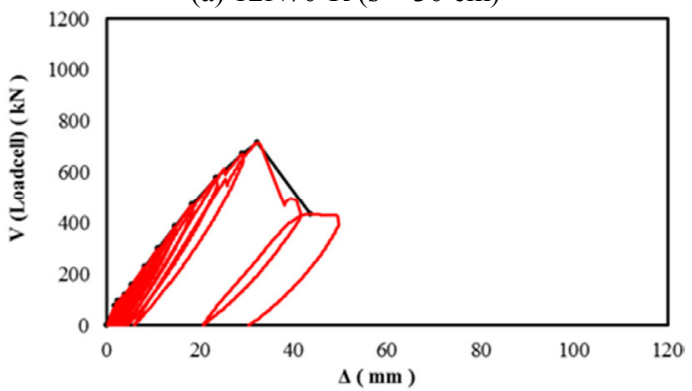

(b) $12 \mathrm{~N} 100-\mathrm{R}(\mathrm{s}=30 \mathrm{~cm})$

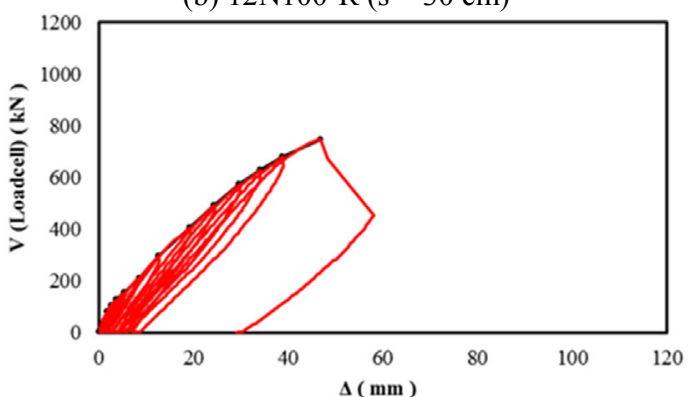

(c) $8 \mathrm{~N} 70-\mathrm{R}(\mathrm{s}=30 \mathrm{~cm})$

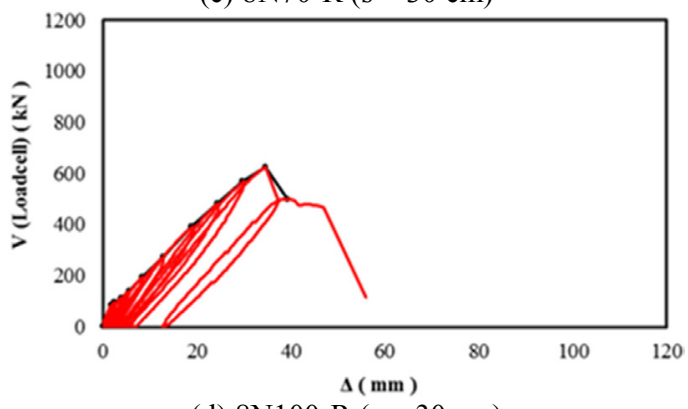

(d) $8 \mathrm{~N} 100-\mathrm{R}(\mathrm{s}=30 \mathrm{~cm})$

Fig. 11 Hysteresis loops and envelope lines of 12 N70, $12 \mathrm{~N} 100,8 \mathrm{~N} 70$ and $8 \mathrm{~N} 100$.

\section{Analysis and discussion}

Experimental data on full-size specimens were used to elucidate the shear crack development of the HSRC shear-critical beams. Not only the shear crack strength and the design formulas that ensure serviceability and reparability, but also the relationship between the width of the shear crack and deformation of the member is suggested.

\subsection{Shear crack strength}

Based on the experimental results, Table 6 presents the shear crack strength of each specimen. Figure 16 shows 


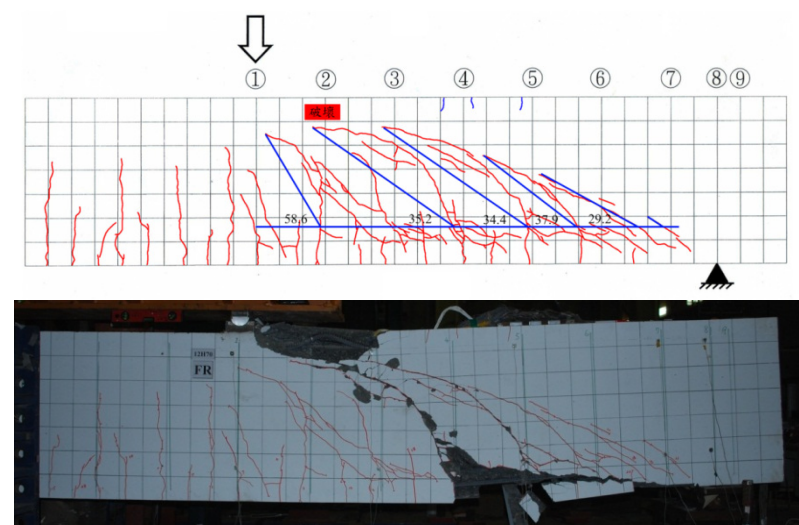

Fig. 12 Shear crack development of the $\mathrm{R}-30$ region of $12 \mathrm{H} 70$.

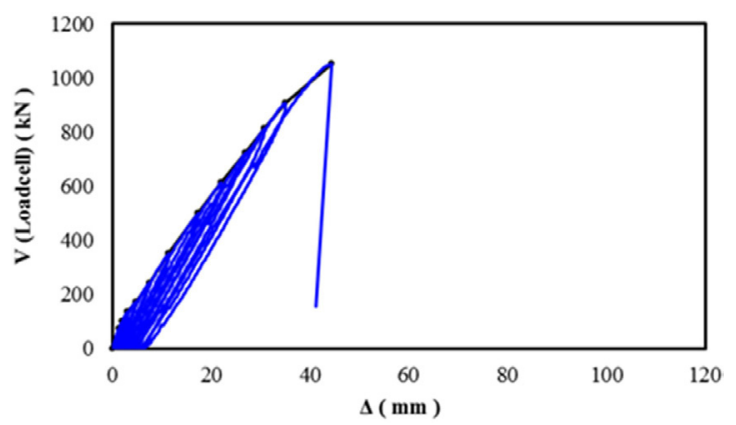

Fig. 13 Hysteresis loop and envelope line of $12 \mathrm{H} 70$ (s = $30 \mathrm{~cm})$.

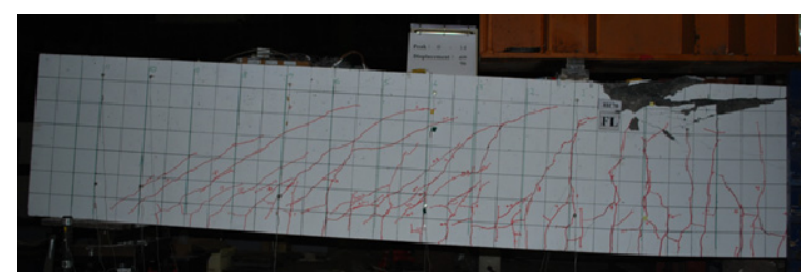

Fig. 14 Failure mode of $8 \mathrm{H} 70$.

that the stresses calculated using Eqs. (3) and (6) are higher than the measured stresses. Restated, Equations (3) and (6) give unconservative predictions of the shear crack strength of the HSRC beam specimens in this work. Equation (3) was derived from fracture theory and modified using the experimental data, while Eq. (6) was based only on the experimental data. Additionally, the research (Nakano et al. 2004) shows the application of Eq. (3) on the high strength concrete. Based on the experimental data, a modification factor of 0.35 is suggested for use in Eq. (3) (rather than the original modification factor of 0.51 ) for the shear crack strength of the HSRC beam specimens. However, since the experimental data are few, this suggested modification factor should be confirmed in the future.

\subsection{Design formulas for ensuring serviceability and reparability}

To ensure serviceability, the peak maximum shear crack width should be maintained under $0.3 \mathrm{~mm}$ under long-term loading. Therefore, based on the experimental

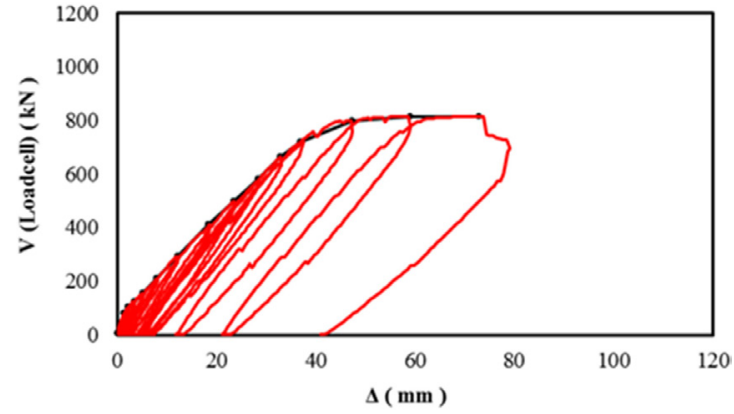

(a) $8 \mathrm{H} 70-\mathrm{R}(\mathrm{s}=30 \mathrm{~cm})$

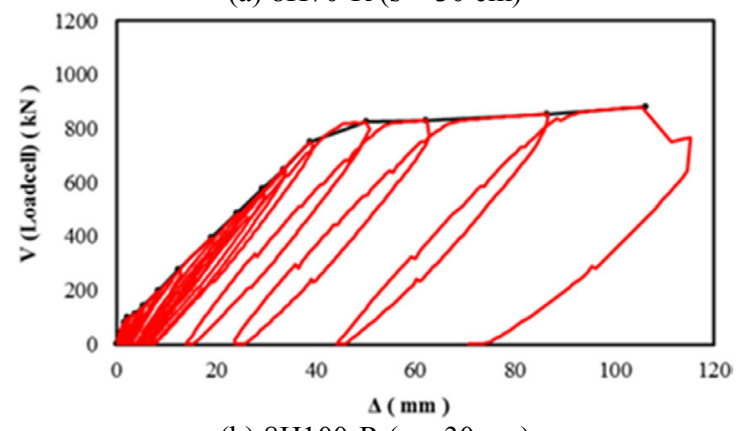

(b) $8 \mathrm{H} 100-\mathrm{R}(\mathrm{s}=30 \mathrm{~cm})$

Fig. 15 Hysteresis loops and envelope lines of $8 \mathrm{H} 70$ and $8 \mathrm{H} 100$.

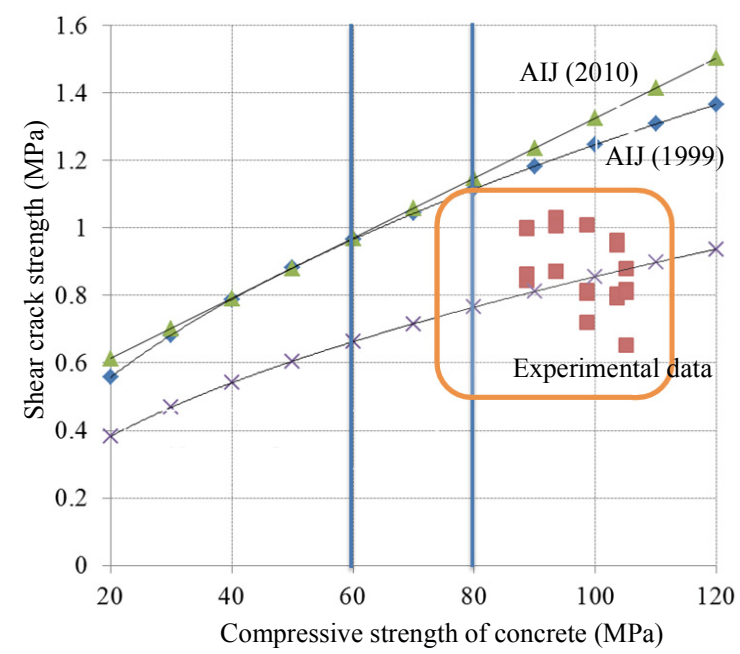

Fig. 16 Relationship between the compressive strength of concrete and shear crack strength.

results, the average shear stresses that yield the peak maximum shear crack width of $0.3 \mathrm{~mm}$ are 1.13-1.59 $\mathrm{MPa}$. Restated, in the experiment herein, when the average shear stress is less than $1.13 \mathrm{MPa}$, the peak maximum shear width can be $\leq 0.3 \mathrm{~mm}$. The average stresses calculated using Eq. (7), recommended in AIJ (2010), are 1.27-1.59 MPa, as listed in Table 7. According to Fig. 17, Equation (7) yields a peak maximum shear crack width, $\leq 0.3 \mathrm{~mm}$, except for the specimen with the stirrup spacing of $300 \mathrm{~mm}$, whose peak maximum shear crack width is $0.35 \mathrm{~mm}$ (stirrup spacing of $200 \mathrm{~mm}$ : $0.28 \mathrm{~mm}$ ).

To ensure the reparability of an HSRC beam member in a medium-magnitude earthquake, the residual maxi- 
Table 7a Allowable shear stresses for controlling the peak maximum shear crack widths within 0.3 and $1.0 \mathrm{~mm}$.

\begin{tabular}{|c|c|c|c|c|c|c|}
\hline Shear stress (MPa) & \multicolumn{2}{|c|}{ Stirrup spacing } & \multicolumn{2}{c|}{ Stirrup strength } & \multicolumn{2}{c|}{ Tensile reinforcement ratio } \\
\hline Maximum crack width (mm) & $200 \mathrm{~mm}$ & $300 \mathrm{~mm}$ & SD785 & SD420 & $\rho_{\mathrm{s}}=0.025$ & $\rho_{\mathrm{s}}=0.017$ \\
\hline 1.0 & 2.92 & 1.61 & 2.67 & 1.61 & 2.33 & 1.61 \\
\hline 0.3 & 1.58 & 1.13 & 1.45 & 1.13 & 1.59 & 1.13 \\
\hline
\end{tabular}

Table $7 \mathrm{~b}$ Allowable shear stresses for controlling the residual maximum shear crack widths within 0.3 and $1.0 \mathrm{~mm}$.

\begin{tabular}{|c|c|c|c|c|c|c|}
\hline Shear stress (MPa) & \multicolumn{2}{|c|}{ Stirrup spacing } & \multicolumn{2}{c|}{ Stirrup strength } & \multicolumn{2}{c|}{ Tensile reinforcement ratio } \\
\hline Maximum crack width (mm) & $200 \mathrm{~mm}$ & $300 \mathrm{~mm}$ & SD785 & SD420 & $\rho_{\mathrm{s}}=0.025$ & $\rho_{\mathrm{s}}=0.017$ \\
\hline 1.0 & 3.31 & 2.34 & - & 2.34 & 2.39 & 2.34 \\
\hline 0.3 & 2.31 & 1.61 & 2.03 & 1.61 & 1.95 & 1.61 \\
\hline
\end{tabular}

Table 8 Peak maximum shear crack widths in terms of various design formulas.

\begin{tabular}{|c|c|c|c|c|c|c|}
\hline \multirow{2}{*}{ Maximum shear crack width (mm) } & \multicolumn{2}{|c|}{ Stirrup spacing } & \multicolumn{2}{c|}{ Stirrup strength } & \multicolumn{2}{c|}{ Longitudinal reinforcement ratio } \\
\cline { 2 - 6 } & $200 \mathrm{~mm}$ & $300 \mathrm{~mm}$ & SD785 & SD420 & $\rho_{\mathrm{s}}=0.017$ & $\rho_{\mathrm{s}}=0.025$ \\
\hline ACI 318 (2011) & 0.59 & 0.43 & 0.54 & 0.56 & 1.24 & 0.43 \\
\hline AIJ (2010) - Eq. (7) & 0.28 & 0.35 & 0.25 & 0.35 & 0.35 & 0.25 \\
\hline AIJ (2010) - Eq. (8) & 0.37 & 0.35 & 0.28 & 0.35 & 0.35 & 0.25 \\
\hline
\end{tabular}

mum shear crack width must be maintained within 0.3 $\mathrm{mm}$, as indicated in Section 2. According to the experimental results, the average shear stresses of the specimens are 1.61-2.31 $\mathrm{MPa}$ while the average stresses calculated using Eq. (8), recommended in AIJ (2010), are 1.32-1.61 MPa, as listed in Table 7. Clearly, regardless of whether the stirrup spacing is 200 or $300 \mathrm{~mm}$, the residual maximum crack width can be maintained within $0.3 \mathrm{~mm}$ by applying Eq. (8). Based on the results, the design formulas that ensure serviceability and reparability, recommended in AIJ (2010), are applied to HSRC beam specimens herein.

As many engineers use the specifications published by ACI 318 for concrete engineering design, the equation for estimating concrete shear strength recommended in ACI 318 (2011) is used herein to discuss shear crack development. To ensure serviceability under long-term loading, the design formula, Eq. (7), recommended in AIJ (2010), can be used to maintain the peak maximum shear crack width, $\leq 0.3 \mathrm{~mm}$ (Table 8). The ratio of the allowable force calculated using Eq. (7) to the concrete shear strength estimated using the equation recommended in ACI 318 (2011) is approximately 0.85. If one standard deviation is used to define the lower bound, then the ratio can be set as 0.75 . Restated, the calculated allowable force that ensures serviceability can be 0.75 times the concrete shear strength that is recommended in ACI 318 (2011).

To ensure reparability under the short-term loading that is induced by a medium-magnitude earthquake, Equation (8) - a design formula recommended in AIJ (2010) - is used to maintain the maximum residual shear crack width, $\leq 0.3 \mathrm{~mm}$ (Table 9). However, for the convenience of Taiwanese engineers, this work suggests that the concrete shear strength that is recommended in ACI 318 (2011) be used instead of Eq. (8) to calculate the allowable force. As listed in Table 9, the concrete shear strength that is recommended in ACI 318 (2011) yields a

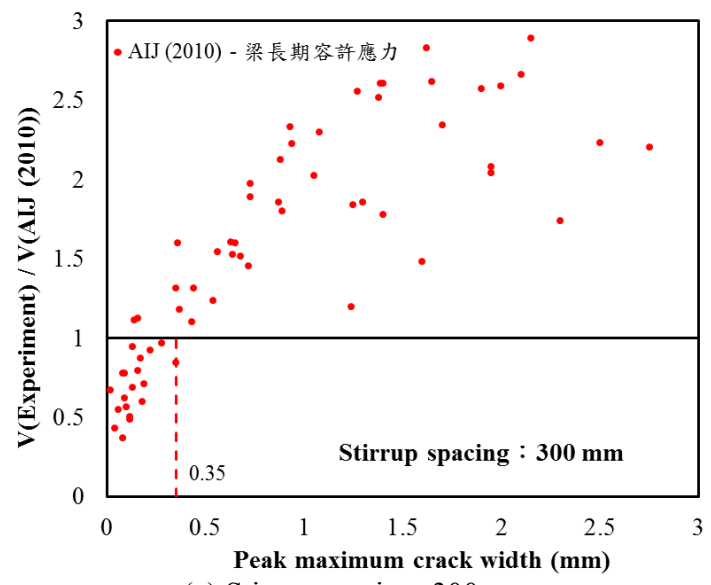

(a) Stirrup spacing: $300 \mathrm{~mm}$

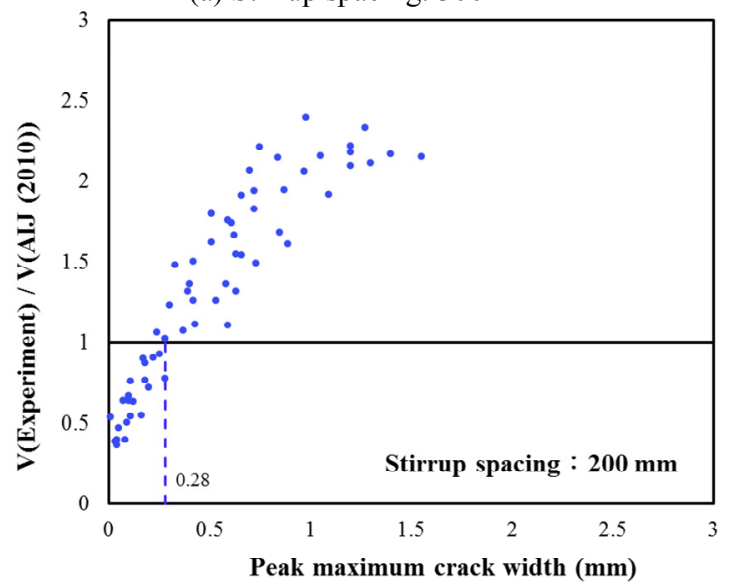

(b) Stirrup spacing: $200 \mathrm{~mm}$

Fig. 17 Peak maximum shear crack widths in terms of Eq. (7).

maximum residual shear crack width, $\leq 0.3 \mathrm{~mm}$. (Only one point exceeds $0.3 \mathrm{~mm}$ in the test data.) Therefore, the equation for estimating of the concrete shear strength of HSRC beam members that is recommended in ACI 318 (2011) is used to ensure the reparability of such members 
Table 9 Residual maximum shear crack widths in terms of various design formulas.

\begin{tabular}{|c|c|c|c|c|c|c|}
\hline \multirow{2}{*}{ Maximum shear crack width (mm) } & \multicolumn{2}{|c|}{ Stirrup spacing } & \multicolumn{2}{c|}{ Stirrup strength } & \multicolumn{2}{c|}{ Tensile reinforcement ratio } \\
\cline { 2 - 7 } & $200 \mathrm{~mm}$ & $300 \mathrm{~mm}$ & SD785 & SD420 & $\rho_{\mathrm{s}}=0.017$ & $\rho_{\mathrm{s}}=0.025$ \\
\hline ACI 318 (2011) & 0.2 & 0.23 & 0.23 & 0.23 & 0.49 & 0.2 \\
\hline AIJ (2010) - Eq. (7) & 0.13 & 0.23 & 0.11 & 0.23 & 0.23 & 0.12 \\
\hline AIJ (2010) - Eq. (8) & 0.15 & 0.23 & 0.15 & 0.23 & 0.23 & 0.15 \\
\hline
\end{tabular}

under short-term loading induced by a medium-magnitude earthquake.

\subsection{Relationship between shear stresses of member and widths of shear cracks}

Based on the experimental results obtained herein, Figures 18 and 19 plot relationships between the shear crack widths and average shear stresses $v(=V / b d)$. The upper bounds on the peak maximum shear crack width and the residual maximum crack width are set to $0.3 \mathrm{~mm}$ and 1.0 $\mathrm{mm}$ (Shimazaki 2009) and their corresponding allowable shear stresses of each specimen are as listed in Table 7. According to Figs. 18 and 19, the peak maximum shear crack width and the residual maximum shear crack width can be reduced by shortening stirrup spacing, increasing stirrup strength and increasing tensile reinforcement ratio. The tensile reinforcement ratio has the weakest effect. Therefore, this work adopts the factors of the compressive strength of concrete, stirrup spacing and stirrup strength to build the relationship curve between shear stresses and widths of shear cracks of HSRC beam members. When the average shear stress and the shear crack width are normalized by the shear crack stress and the average strain of stirrup (Eq. (15)), respectively, it can be found that the relationship curves between shear stresses and widths of shear cracks have the linear tendency in logarithmic axes, as show in Figs. 20 and 21. This work does a regression analysis for the data shown in Figs. 20 and $\mathbf{2 1}$ to build the formulas, which can be used to describe the relationship between shear stresses and widths of shear cracks. For the engineering use in HSRC beam members, Equations (16) and (17) with one derivation of model error are suggested to be the prediction formulas for average shear stresses $v$ corresponding to a specified peak maximum shear crack width $W_{p s, \max }$ and residual shear crack width $W_{s, \max }$, respectively. Restated, engineers can use these equations to predict the peak maximum shear crack width and residual maximum shear crack width for HSRC beam members under the loading.

$$
\begin{aligned}
& \varepsilon_{v y}=\frac{a_{w} f_{v y}}{b s E_{s}} \\
& \frac{v}{v_{c r}}=0.39 \times\left(\left(\frac{W_{p s, \text { max }}}{d}\right) / \varepsilon_{v y}\right)^{0.33} \\
& \frac{v}{v_{c r}}=0.60 \times\left(\left(\frac{W_{s, \text { max }}}{d}\right) / \varepsilon_{v y}\right)^{0.28}
\end{aligned}
$$

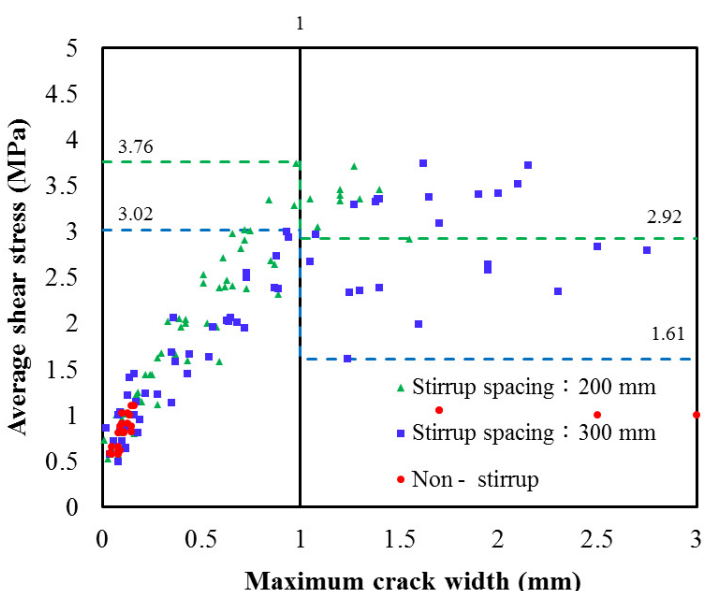

(a) Stirrup spacing

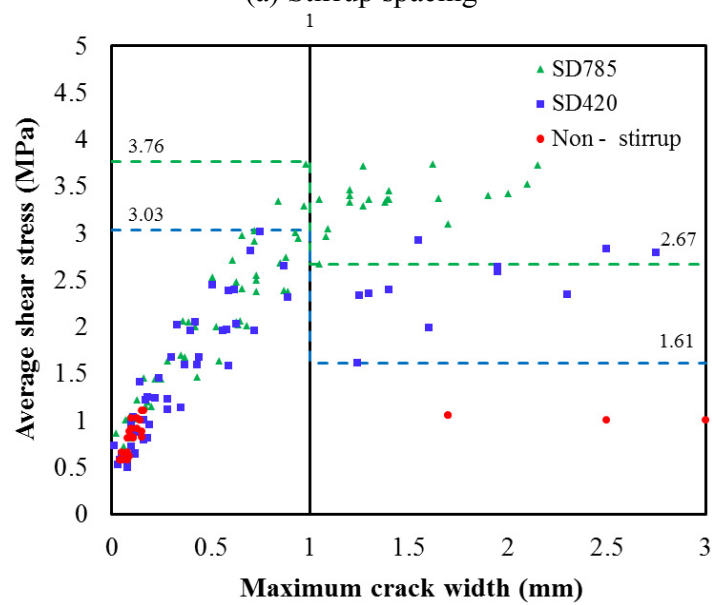

(b) Stirrup strength

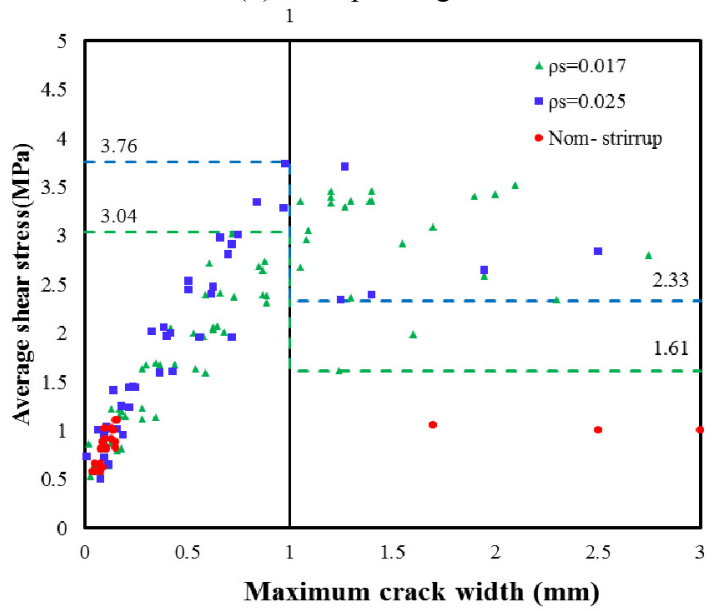

(c) Longitudinal reinforcement ratio

Fig. 18 Relationship between the peak maximum shear crack width and average shear stress. 


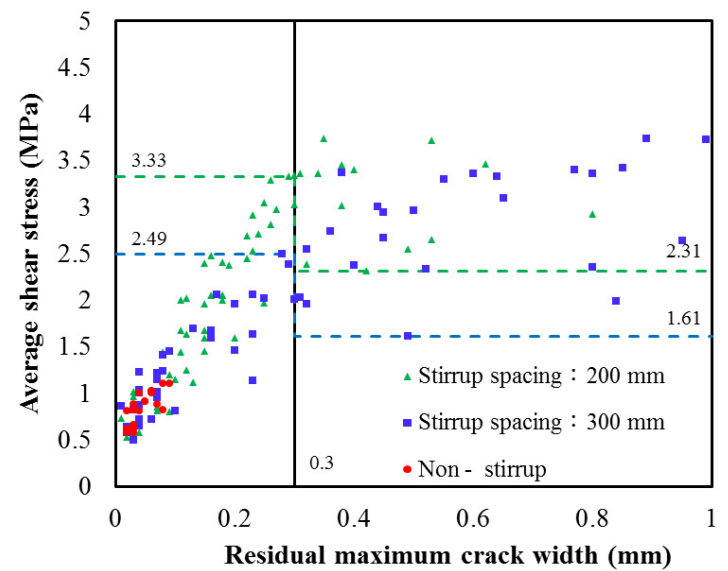

(a) Stirrup spacing

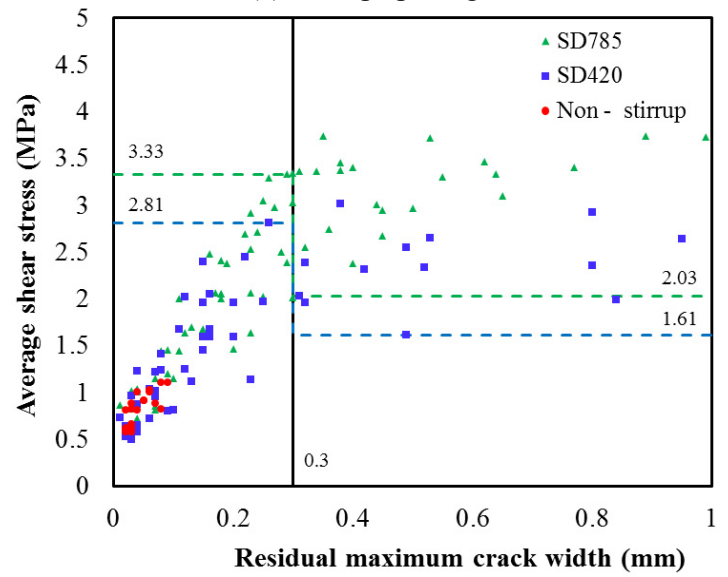

(b) Stirrup strength

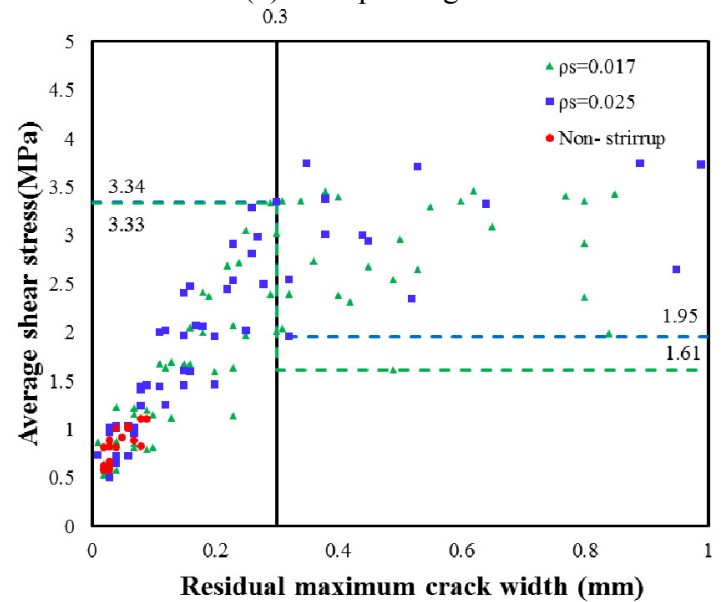

(c) Tensile reinforcement ratio

Fig. 19 Relationship between the residual maximum shear crack width and average shear stress.

where $f_{v y}$ is the yielding stress of stirrup (MPa); $E_{s}$ is the elasticity modulus of stirrup (MPa); $d$ is the effective depth of a member's cross section ( $\mathrm{mm}) ; v_{c r}$ is the shear crack strength of concrete as stated in Sec. $4.1(\mathrm{MPa})$. Additionally, $v / v_{c r}$ should be $\geqq 1.0$ in Eqs (16) and (17).

\subsection{Relationship between deformation of member and widths of cracks}

The relationship between the residual total shear crack

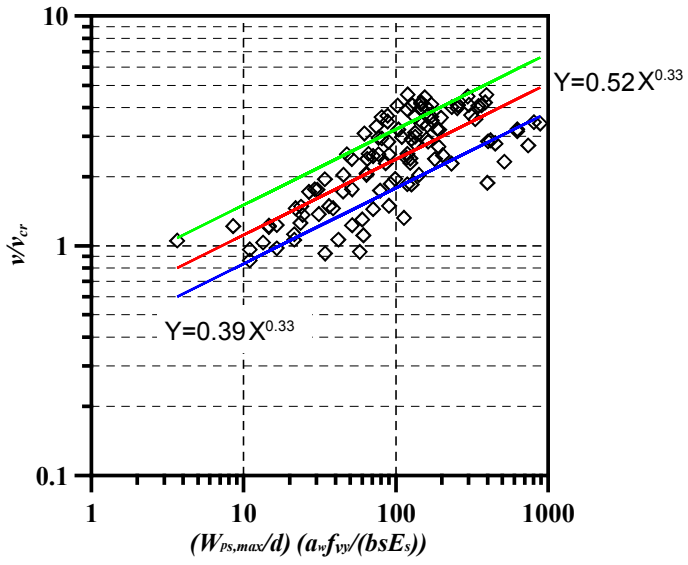

Fig. 20 Regression analysis for the relationship between the peak maximum shear crack width and average shear stress.

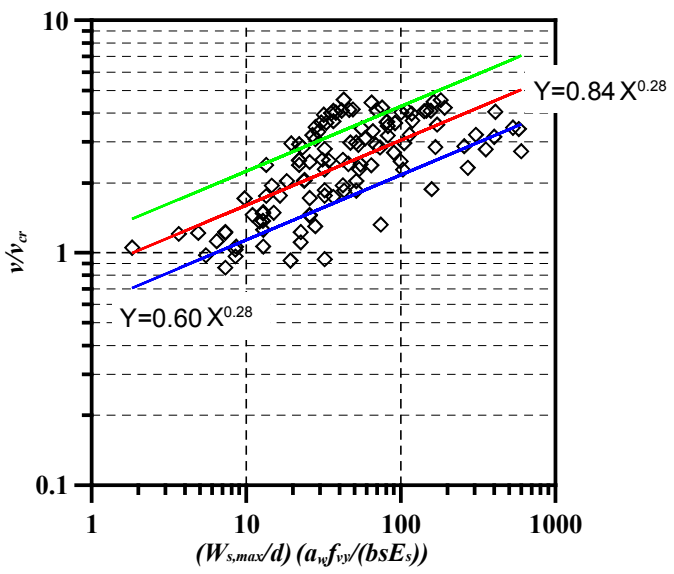

Fig. 21 Regression analysis for the relationship between the residual maximum shear crack width and average shear stress.

widths and the residual maximum shear crack width is experimentally investigated. Notably, this relationship can be used to estimate the maximum width of residual shear cracks and to elevate damage to a column or beam member under seismic loading, as mentioned in Section 2.4. According to Fig. 22, the ratio of the residual total shear crack widths to the residual maximum shear crack width is approximately increasing linearly along the shear deformation within $1.2 \mathrm{~mm}$ of the shear deformation and then it remains almost constant as the shear deformation increases beyond $1.2 \mathrm{~mm}$. The small stirrup spacing and high-strength stirrups reduce the residual shear crack width. Therefore, the average ratio exceeds that obtained with a small spacing and normal-strength stirrups. The suggested ratio for a normal-strength $\mathrm{RC}$ column or beam member in the literature is 3.0-4.0 (AIJ 1999). The results herein indicate that the average ratio for the HSRC beam specimens is approximately 4.5. Therefore, for assessing crack-based damage, we recommend setting the ratio to 4.0 in estimating the residual maximum shear cracking.

Based on Eq. (14) and the ratio of the residual total shear crack width to the residual maximum shear crack 


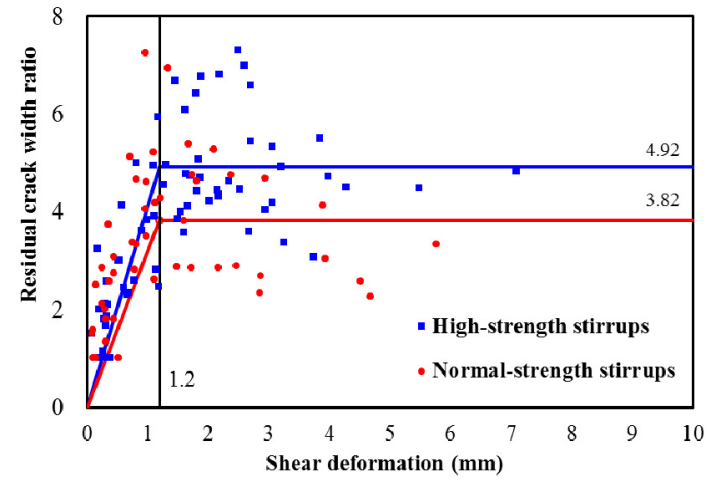

(a) Strength of stirrups

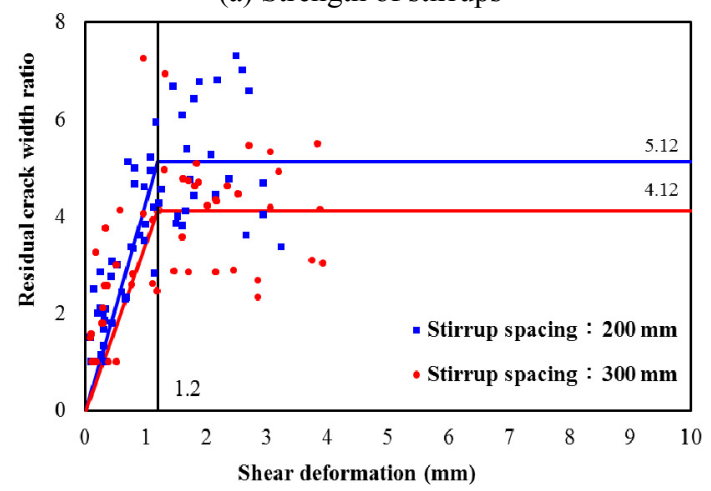

(b) Spacing of stirrups

Fig. 22 Ratio of the residual total shear crack widths to the residual maximum shear crack width.

width, 4.0, the latter was used to calculate the residual shear deformation of each specimen, as shown in Fig. 23. Additionally, the angle of the primary shear crack was used to estimate $\cos \beta$. Clearly, Eq. (14) yields a conservative prediction of residual shear deformation for each specimen. Figure 23 also shows that the ratio of the residual total shear crack width to the residual maximum shear crack width, 4.0, provides a good estimate of the total residual shear crack widths.

Figure 24 shows the ratio of maximum peak shear crack width to the residual maximum crack width. For normal-strength $\mathrm{RC}$ members, the recommended value in the literature is 2.0 (AIJ 1999). The purpose of this ratio is to define the position of each performance point on the structural capacity curve (force-displacement curve) (Fig. 3b) that can be used to confirm the performance points, including the serviceability, reparability and safety in a structural analysis. Based on the experimental results, the ratio can be increased by shortening the stirrup spacing and increasing the stirrup strength, and its average value is 2.44 . Therefore, this work suggests that the applicable value of an HSRC shear-critical beam is 2.5 .

\section{Conclusions}

In this work, stirrup strength, spacing, and tensile reinforcement ratio were used as parameters to investigate the development of shear cracks in shear-critical HSRC beams. To quantify damage, experimental measure-

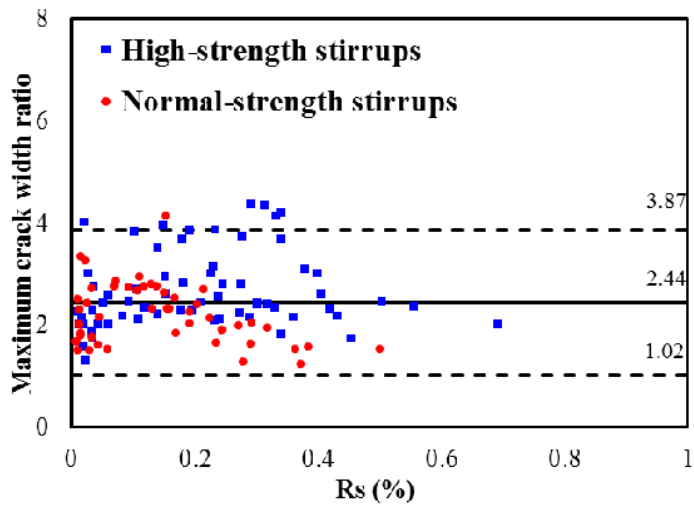

(a) Stirrup strength

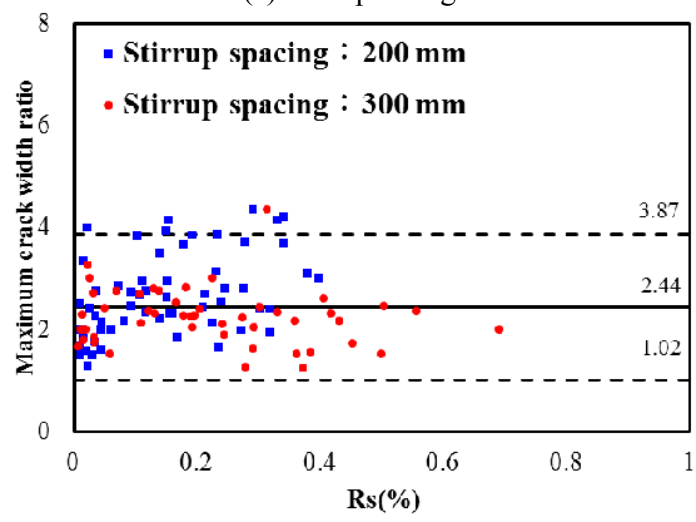

(b) Stirrup spacing

Fig. 24 Ratio of peak maximum shear crack width to residual maximum shear crack width.

ments of shear cracks are made to identify the relationship between the shear crack width and the deformation of a member.

Based on the analysis and discussion of the experimental data, many conclusions are drawn as follows:

\section{(a) Shear crack strength:}

Based on experimental data, in the calculation of the shear crack strength of HSRC beam specimens, this work suggests that a modification factor of 0.35 be used in Eq. (3) (original modification factor for normalstrength RC member is 0.51). However, owing to the lack of experimental data herein, this suggested modification factor should be confirmed in the future.

\section{(b) Ensuring serviceability:}

Based on the experimental results obtained herein, the average shear stresses at the peak maximum shear crack width of $0.3 \mathrm{~mm}$ are $1.13-1.59 \mathrm{MPa}$. The average stresses that are calculated using Eq. (7), recommended in AIJ (2010), are 1.27-1.59 MPa. Restated, Eq. (7) yields a peak maximum shear crack width, $\leq 0.3 \mathrm{~mm}$, except for the specimen with the stirrup spacing of 300 $\mathrm{mm}$, whose peak maximum shear crack width is 0.35 $\mathrm{mm}$. (For the specimen with the stirrup spacing of 200 $\mathrm{mm}$, the corresponding value is $0.28 \mathrm{~mm}$ ). Based on these results, the design formula that ensures serviceability and is recommended in AIJ (2010) (Eq. (7)) can 


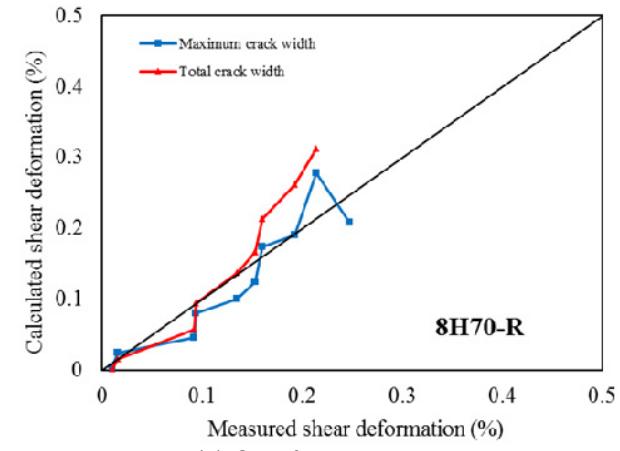

(a) $8 \mathrm{H} 70$

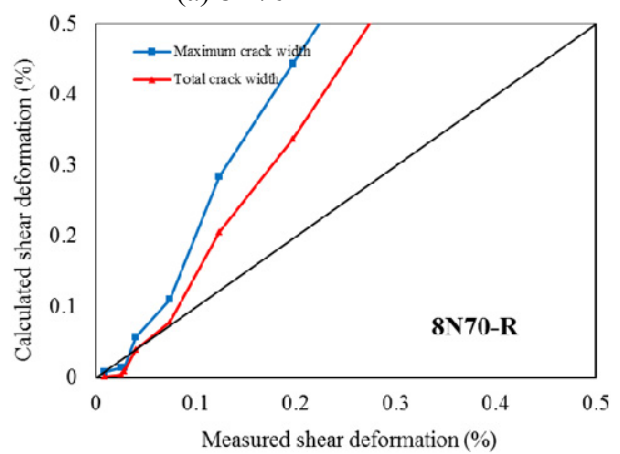

(c) 8 N70

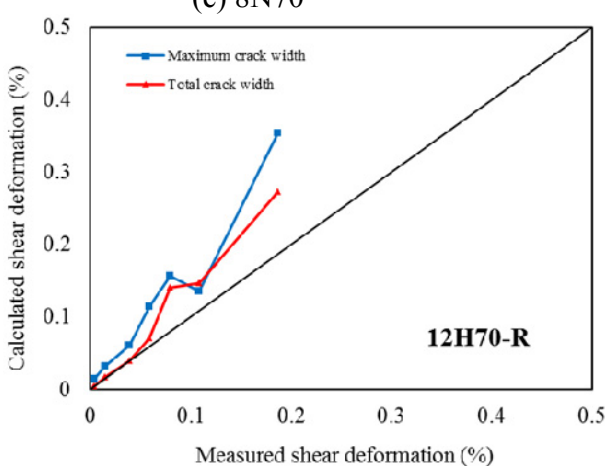

(e) $12 \mathrm{H} 70$

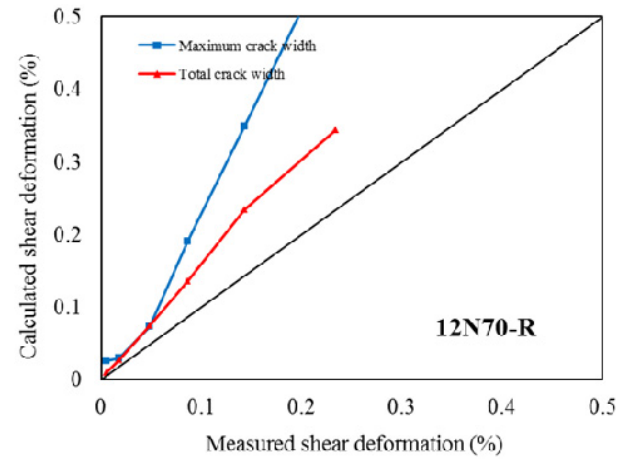

(g) $12 \mathrm{~N} 70$

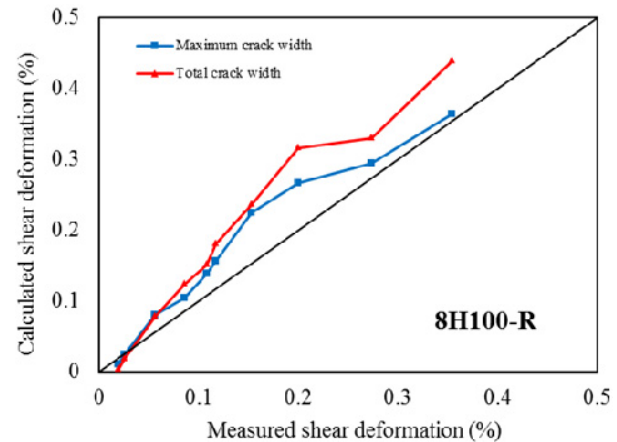

(b) $8 \mathrm{H} 100$

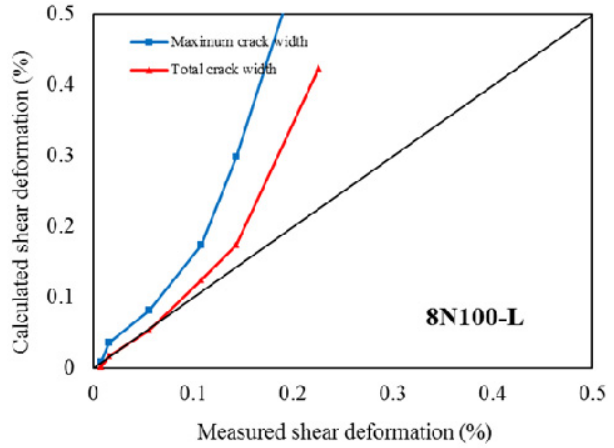

(d) $8 \mathrm{~N} 100$

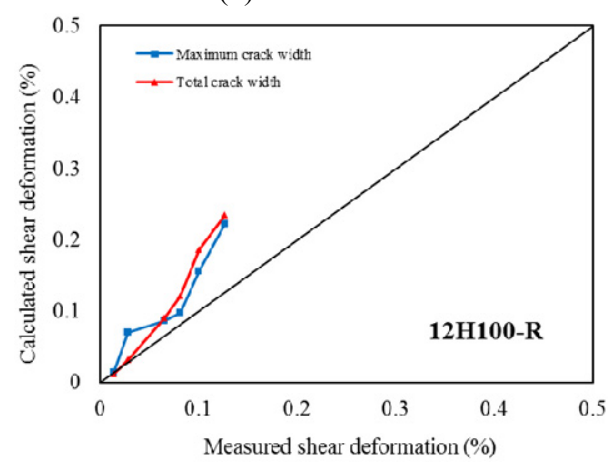

(f) $12 \mathrm{H} 100$

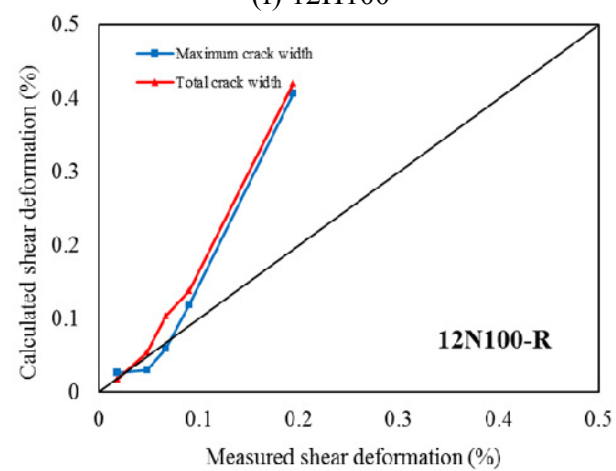

(h) $12 \mathrm{~N} 100$

Fig. 23 Comparison of the calculated shear deformation and measured shear deformation.

be applied to shear-critical HSRC beams.

\section{(c) Ensuring reparability:}

Based on the experimental results, the average shear stresses of the specimens are 1.61-2.31 MPa whereas the average stresses, calculated using Eq. (8), recommended in AIJ (2010) are 1.32-1.61 MPa. Regardless of whether the stirrup spacing is 200 or $300 \mathrm{~mm}$, the re- sidual maximum crack width can be kept below the recommended value of $0.3 \mathrm{~mm}$ using Eq. (8). Based on these results, the design formula that ensures reparability and is recommended in AIJ (2010) (Eq. (8)) can be applied to shear-critical HSRC beams.

(d) Relationship between shear stresses and widths of shear cracks: 
for HSRC beam members, Equations (16) and (17) are suggested to be the prediction formulas for average shear stresses corresponding to a specified peak maximum shear crack width and residual shear crack width, respectively. Restated, engineers can use these equations to predict the peak maximum shear crack width and residual maximum shear crack width for HSRC beam members under the loading.

\section{(e) Residual maximum shear crack:}

According to the experimental results, the small stirrup spacing and high-strength stirrups reduce the residual shear crack width. The results herein indicate that the average ratio of the residual total shear crack width to the residual maximum shear crack width for the HSRC beam specimens is approximately 4.5. In the crack-based damage assessment, this work recommends setting the ratio to 4.0 in estimating residual maximum shear cracking. Additionally, the ratio of the maximum peak shear crack width to the residual maximum crack width can be increased by shortening the stirrup spacing and increasing the stirrup strength, and the overall average value is 2.44 . This work suggests that the applicable value of an HSRC shear-critical beam is 2.5.

\section{(f) Residual shear crack width and deformation of member:}

Based on Eq. (14) and the ratio of the residual total shear crack widths to the residual maximum shear crack width of 4.0, a conservative prediction of the shear deformation of each specimen can be estimated. Additionally, the ratio of the residual total shear crack width to the residual maximum shear crack width, 4.0, provided a good estimate of the total residual shear crack widths.

Besides of the post-earthquake damage assessment, these results can also be used to build the performance-based design for HSRC structures. However, since many factors affect the shear crack development of a HSRC member, e.g., the concrete-cover thickness, ratio of the span to depth and section size, the suggestions stated above need to be verified further in the future.

\section{Reference}

ACI., (2010). "Report on high-strength concrete." ACI Committee 363. American Concrete Institute.

ACI., (2011). "Building code requirements for structural concrete." ACI Committee 318. American Concrete Institute.

AIJ., (2010). "Standard for structural calculation of reinforced concrete structures." Tokyo: Architectural
Institute of Japan.

AIJ., (1999). "Design guidelines for earthquake resistant reinforced concrete buildings based on inelastic displacement concept." Architectural Institute of Japan, Tokyo, Japan. (in Japanese)

FIP/CEB., (1990). "High strength concrete, State of the art report." Bulletin d'Information, No. 197, August 1990.

JBDPA., (2001). "Standard for post-earthquake damage level classification of reinforced concrete building." Tokyo: The Japan Building Disaster Prevention Association.

Maeda, M. and Kang, D. E., (2009). "Post-earthquake damage evaluation for reinforced concrete buildings." Journal of Advanced Concrete Technology, 7(3), 327-335.

Nakano, Y., Maeda, M., Kuramoto, H. and Murakami, M., (2004). "Guideline for post-earthquake damage evaluation and rehabilitation of RC buildings in Japan." 13th World Conference on Earthquake Engineering, Vancouver, B.C., Canada (Paper No. 124).

Patwardhan, C., (2005). "Shear strength and deformation modeling of reinforced concrete column." Ohio State University, Columbus, USA (Master thesis).

Sezen, H., (2002). Seismic behavior and modelling of reinforced concrete building columns. University of California, Berkeley, USA 2002 (Doctoral thesis) .

Setzler, E. J., (2005). "Modeling the behavior of lightly reinforced concrete columns subjected to lateral loads." Ohio State University, Columbus, USA (Master thesis).

Silva, S. D., Mutsuyoshi, H. and Witchukreangkrai, E. (2008). "Evaluation of shear crack width in I-shaped prestressed reinforced concrete beams." Journal of Advanced Concrete Technology, 6(3), 443-458.

Shimazaki, K., (2009). "Evaluation of shear crack width based on shear force ratio." AIJ Journal of Technology and Design (Architectural Institute of Japan, AIJ), 15(29), 139-142. (in Japanese)

Yoshimura, M and Takaine, Y., (2005). "Formulation of post-peak behavior of old reinforced concrete columns including collapse drift.” J. Struct Constr Eng, 587, 163-171. (in Japanese)

Zakaria, M., Ueda, T., Wu, Z. and Liang, M., (2009). "Experimental investigation on shear cracking behavior in reinforced concrete beams with shear reinforcement." Journal of Advanced Concrete Technology, 7(1), 79-96. 